University of Montana

ScholarWorks at University of Montana

Graduate Student Theses, Dissertations, \&

Professional Papers

2017

\title{
An Investigation of the Relations Between Stress and Prospective Memory
}

Brandon T. Stewart

University of Montana, Missoula

Follow this and additional works at: https://scholarworks.umt.edu/etd

Part of the Biological Psychology Commons, and the Cognitive Psychology Commons Let us know how access to this document benefits you.

\section{Recommended Citation}

Stewart, Brandon T., "An Investigation of the Relations Between Stress and Prospective Memory" (2017). Graduate Student Theses, Dissertations, \& Professional Papers. 10995.

https://scholarworks.umt.edu/etd/10995

This Thesis is brought to you for free and open access by the Graduate School at ScholarWorks at University of Montana. It has been accepted for inclusion in Graduate Student Theses, Dissertations, \& Professional Papers by an authorized administrator of ScholarWorks at University of Montana. For more information, please contact

scholarworks@mso.umt.edu. 


\title{
AN INVESTIGATION OF THE RELATIONS BETWEEN STRESS AND PROSPECTIVE
}

\section{MEMORY}

By

\section{BRANDON TAYLOR STEWART}

Bachelor of Arts in Psychology, The University of Montana, Missoula, MT, 2013

Thesis

presented in partial fulfillment of the requirements

for the degree of

\author{
Master of Arts \\ in Clinical Psychology \\ The University of Montana \\ Missoula, MT
}

May 2017

Approved by:

Scott Whittenburg, Dean of The Graduate School

Graduate School

Craig P. McFarland, PhD, Chair

Department of Psychology

Stuart Hall, PhD

Department of Psychology

Allen Szalda-Petree, PhD

Department of Psychology

Catherine Off, $\mathrm{PhD}$

Department of Communicative Sciences and Disorders 
Prospective memory (PM) is a future-oriented memory system that entails "remembering to remember" intentions, or to perform actions in the future. People spend significant portions of their day-to-day lives forming and acting on intentions, and the ability to successfully generate, retain, and complete these intentions has important implications for one's daily functioning and quality of life. Another common human experience is stress, whether that be short-term, acute stress, or long-term, chronic stress. Despite the significance and ubiquity of both PM and stress, the research base documenting the relations between them is sparse. This topic area necessitates additional research to delineate the interactions between stress and PM. The current study provides novel data towards that effort, and is the first empirical study investigating how stress relates with non-focal event-based PM. The results demonstrate that acute stress induction procedures did not produce significant differences in non-focal event-based PM performance, or time-based PM performance. However, among a smaller subset of those in the experimental group who reported the highest levels of stress, increasing levels of acute stress correlated significantly with higher non-focal event-based PM performance. Further, stress at the outset of the study correlated significantly with enhanced time-based PM as well as monitoring behavior. These results may have important implications and contribute to our developing understanding of the relations between stress and the ability to carry out intentions in the future.

Keywords: Stress, Prospective Memory, Intentions, Event-based, Time-based 
An Investigation of the Relations Between Stress and Prospective Memory

\section{Introduction}

The human memory system is vital for everyday functioning, and enables one to recall information from the past, as well as plan for the future. Thus, memory is multidirectional with regards to temporal orientation (Tulving, 1983; Einstein \& McDaniel, 1990; 1996; McDaniel \& Einstein, 2007; Unsworth, McMillan, Brewer, \& Spillers, 2013). Retrospective memory (RM) refers to remembering details of the past (Tulving, 1983). The RM system is very important for many tasks in everyday life, and failures of this memory system can lead to a variety of repercussions (Unsworth et al., 2013). For example, RM failures may lead to the forgetting of names, phone numbers, conversations, locations of objects, and information for exams or homework (Crovitz \& Daniel, 1984; Terry, 1988; Unsworth et al., 2013). While the significance of past-oriented memory is readily acknowledged, Klein (2013) asserts that "memory is of the past, but about the future," and argues for the importance of understanding memory that is temporally oriented towards the future (p. 231). Prospective memory (PM) is a type of memory that involves remembering to perform actions in the future (Brandimonte, Einstein, \& McDaniel, 1996; Einstein \& McDaniel, 1990; 1996; Ellis, 1996; McDaniel \& Einstein, 2007; McDaniel, Glisky, Guynn, \& Routhieaux, 1999; McFarland \& Glisky, 2011; 2009). For example, one relies on PM when remembering to take medication according to a schedule, or to attend a meeting.

\section{Prospective Memory}

Prospective remembering is fundamental for everyday life, and individuals can spend much of each day forming and acting on intentions. For example, remembering to attend appointments, meetings, or turn in projects or assignments on time, rely on the ability to remember and execute intentions. Further, remembering to go to the grocery store after work, 
purchase gifts for birthdays or anniversaries, and various other life activities, also depend on PM.

Despite the extent to which people rely on this memory system, failure to complete future intentions is quite common. In fact, PM failures may even account for over half of everyday forgetting (Crovitz \& Daniel, 1984). Prospective memory first involves the formulation of an intention, followed by execution of that intention at some point in the future. For example, one might form an intention in the morning to pick up an important prescription from the drug store later that day on the way home from work. As the example implies, PM entails a delay between the formation of an intention and the completion of that intention, which can last for minutes, hours, or days (Brandimonte et al., 1996; Ellis, 1996; McDaniel \& Einstein, 2000; Smith, 2003). During a delay, people often engage in other work, academic, recreational, or social activities unrelated to the PM intention.

The execution of PM intentions occurs after the passing of a certain amount of time, or upon recognizing an environmental cue associated with a previously formed intention (Gordon, Shelton, Bugg, McDaniel, \& Head, 2011; Marsh, Hicks, \& Watson, 2002; McFarland \& Glisky, 2011). Consequently, researchers typically divide PM into two forms: Time-based and eventbased PM (Einstein \& McDaniel, 1990; 1996; Kliegel, Martin, McDaniel, \& Einstein, 2001; Smith \& Bayen, 2005). Time-based PM involves performing an intention at a specific time in the future, or following the passage of a certain amount of time. Common examples of time-based PM include remembering to attend an appointment at 9:00 am, or remembering the take cookies out of the oven after 20 minutes. In contrast, event-based PM involves performing an action in the presence of an environmental stimulus or cue that signals the appropriateness of executing a previously formed intention (Einstein \& McDaniel, 1990; 1996). An example of event-based PM is remembering to tell a friend or colleague an important message when you see that person next. 
In that context, the presence of the friend serves as a stimulus or cue that may remind one to deliver the intended message.

Prospective memory incorporates RM in that one must recall a previously formed intention in order to successfully complete the PM. However, several key features distinguish PM from RM (Einstein \& McDaniel, 1990; 1996; McDaniel \& Einstein, 2000). First, in tasks of prospective remembering, participants typically engage in an unrelated ongoing activity, and may need to monitor the environment for the appropriate time or context in which to perform an intended action. Experimental tasks of RM lack an ongoing task, but rather, involve asking participants to recall previously presented information. By requesting participants to recall details of previously presented information (e.g., a word list or narrative), subjects enter what Tulving (1983) refers to as retrieval mode. In contrast, retrieval of intentions within a PM task must ensue without external prompting (i.e., there is no direct request to retrieve intentions), requiring some degree of self-initiation. Upon identification of a PM cue, one must inhibit the allocation of attentional resources towards an ongoing activity, and switch attention from the ongoing task to the PM task (Einstein, Holland, McDaniel, \& Guynn, 1992; Einstein \& McDaniel, 1990; 1996; McFarland \& Glisky, 2011; Smith, 2003; Smith \& Bayen, 2004; Zollig et al., 2007). Researchers often refer to these additional unsolicited cognitive processes as "selfinitiated processing" (Craik, 1986).

Both time-based and event-based PM rely on self-initiated processing (Brandimonte et al., 1996; Kliegel et al., 2001). However, these two forms of PM differ in the degree to which they rely on self-initiated processing (d'Ydewalle, Bouchaert, \& Brunfaut, 2001; McDaniel, Einstein, \& Rendell, 2008). For instance, since time-based PM lacks externally presented cues to signal appropriate retrieval of previously formed intentions, this form of PM relies more on self- 
initiated activity (e.g., monitoring the time) than event-based PM (d'Ydewalle et al., 2001;

Einstein \& McDaniel, 1990; Kliegel et al., 2001). Kliegel et al. (2001) provided evidence supporting the idea that time-based PM requires additional self-initiated processing and allocation of attentional resources by demonstrating that the importance of a PM task affects time-based but not event-based PM task performance. Specifically, the authors found a significant importance effect in monitoring responses, such that participants in the high importance condition monitored the clock more frequently. The authors concluded that importance impacted time-based PM performance to a higher degree than event-based PM performance due to increased requirements of self-initiated strategic rehearsal and monitoring of the environment for the presence of a time-based target cue (Kliegel et al., 2001).

Time-based PM tasks characteristically require the execution of a PM intention at precise moments in time, such as by pressing a button after a certain time interval elapses (e.g., fiveminute intervals), while at the same time performing an ongoing task (Brandimonte et al., 1996; Kliegel et al., 2005; McDaniel \& Einstein, 2007; Smith, 2003). As mentioned previously, timebased PM tasks lack external (environmental) cues. Therefore, one must monitor the passage of time to determine if a specified amount of time has passed (Einstein \& McDaniel, 1990; Harris \& Wilkins, 1982; McFarland \& Glisky, 2011; 2009). On the other hand, event-based PM tasks customarily involve execution of a PM intention (e.g., pressing a button) when an associated external cue is presented, such as a target word, embedded within an ongoing task (Brandimonte et al., 1996; Kliegel et al., 2005; McDaniel \& Einstein, 2007; Smith, 2003). Monitoring for the presence of an event-based cue may still be required for successful PM, however, depending upon several factors, including ongoing task difficulty, cue salience, the number of target events, 
and individual differences such as age and health status (Einstein et al., 2005; McDaniel \& Einstein, 2000; Scullin, McDaniel, \& Einstein, 2010).

An important feature of event-based PM tasks, and one that can determine whether monitoring is required, is the focality of PM target cues. Focality refers to the degree to which an ongoing task encourages processing of the PM cue (Einstein et al., 2005; McDaniel \& Einstein, 2007). For example, in the laboratory, a lexical decision task may serve as the ongoing activity, and a word (such as "president") may be the PM cue. In this case, the ongoing lexical decision task encourages focal processing of the PM cue. That is, both the lexical decision task and PM cue recognition require semantic processing. In contrast, if the PM cue is the syllable "tor," then there is less overlap between the processing required of a lexical decision task and that required for PM cue detection. For an everyday example of a focal cue, one may drive home from work, see the grocery store at the corner of an intersection, and thus, remember a previous intention to shop for groceries that day. Using the same example, the grocery store would be a non-focal PM cue if it were located around the corner or otherwise obscured from view. Because the obscured grocery store (i.e., a nonfocal cue) is not directly encountered, and therefore not processed on the drive home, more resource-demanding, self-initiated processes must be engaged to maintain the intention and to anticipate the appropriate point on one's drive home at which they will need to turn into the grocery store (Einstein et al., 2005; Kliegel, Jäger, \& Phillips, 2008; McDaniel, Shelton, Breneiser, Moynan, \& Balota, 2011; Rose, Rendell, McDaniel, Aberle, \& Kliegel, 2010; Tam \& Schmitter-Edgecombe, 2013).

Due to the self-initiated processing that PM tasks demand, successful completion of PM tasks likely depends on the deployment of various executive functions. A PM task entails four distinct phases: (1) intention formation - where planning and formation of an intention takes 
place, (2) intention retention - the period in which an intention is maintained in long-term memory throughout a delay (often filled with an ongoing activity), (3) intention initiation - the time at which execution of an intention is (or should be) commenced, and (4) intention execution - when execution of the intended action occurs (Brandimonte et al., 1996; Ellis, 1996; Kliegel, Altgassen, Hering, \& Rose, 2011; Kliegel, Martin, McDaniel, \& Einstein, 2002). Each of these steps are dependent, at least in part, on intact executive functioning, which are goal-oriented processes that enable one to monitor the environment, switch between tasks or stimuli (shift), plan, maintain information in working memory (WM), and inhibit actions or responses (Maylor, 1996; Martin, Kliegel, \& McDaniel, 2003; McDaniel \& Einstein, 2000; McFarland \& Glisky, 2009; Miyake et al., 2000; Kliegel et al., 2011; Rose et al., 2010; Salthouse, Berish, \& Siedlecki, 2004; Schnitzspahn, Stahl, Zeintl, Kaller, \& Kliegel, 2013; Smith, 2003; Smith \& Bayen, 2004). These executive functions are the focal point of prominent theories of PM.

Theories of Prospective Memory. McDaniel and Einstein (2000) proposed the multiprocess theory of PM as a framework for understanding the cognitive processes involved in PM, and the contexts in which different processes may or may not be required for successful PM. McDaniel and Einstein (2000) assert that there are multiple processes one might use to successfully execute a PM intention. For example, under some conditions (e.g., a non-focal cue) monitoring may be required to identify a PM cue. In other situations, monitoring may not be required (e.g., a focal cue) and a PM cue can enable spontaneous retrieval of an intention (McDaniel \& Einstein, 2000; Scullin et al., 2010). Several studies provide empirical support for the multiprocess theory (Einstein et al., 2005; Guynn, 2003; Marsh, Hicks, Cook, Hansen, \& Pallos, 2003; McDaniel \& Einstein, 2000; Scullin et al., 2010). 
In laboratory-based investigations, measuring monitoring within time-based PM tasks entails differing procedures from that of event-based PM tasks. In time-based tasks, one measures monitoring behavior directly. Participants in time-based tasks are often required press a computer key to reveal the elapsed time since the start of the task. Each recorded key press serves as a measure of monitoring behavior, as they indicate that a participant is checking the clock for the appropriate time to respond. In contrast, one infers monitoring for an event-based cue by reduced ongoing task performance in the context of a PM task. To calculate diminished ongoing task performance, participants complete two blocks of an ongoing task (e.g., a lexical decision task). In the first block, participants complete the ongoing task in isolation, and in the second block, they complete the ongoing task along with an embedded PM task. If participant performance on the ongoing task is poorer in the second block (when the ongoing task has an embedded PM task) than in the first (with the ongoing task in isolation), then this may illustrate that they were monitoring for an event-based cue, leading to a cost in ongoing task performance (Marsh et al., 2003; Smith, 2003; Einstein et al., 2005).

Costs to ongoing task performance (by monitoring for an event-based PM target cue) may result from the division of limited cognitive resources between an ongoing task and monitoring for PM tasks. Thus, when engaging in resource-demanding monitoring of the environment in search of a PM target cue, performance on ongoing tasks often suffers as a result (Marsh et al., 2003; Smith, 2003; Smith \& Bayen, 2004). For example, Smith (2003) found that ongoing task performance deteriorates when participants divide resources between the ongoing activity and the PM task. Certain features of the ongoing task can influence the amount of attentional resources required to monitor for a PM cue, such as the extent to which an ongoing task encourages focal processing of a PM cue. 
Per McDaniel \& Einstein (2000), a non-focal PM cue requires considerable attentional resources to monitor the environment for a PM cue. Conversely, if an ongoing task encourages focal processing of a PM cue, then spontaneous recognition of the PM cue and involuntary retrieval of an intention might ensue (Einstein et al., 2005; McDaniel \& Einstein, 2000). In other words, focal cues may therefore "pop out," and their detection may require less active monitoring when compared to non-focal cues. With regards to spontaneous retrieval, the other route to intention retrieval in the multiprocess model, researchers demonstrate results consistent with the notion of relatively automatic and rapid retrieval of PM intentions, with little consequence to ongoing task performance (Einstein, McDaniel, Shank, \& Mayfield, 2002; Einstein et al., 2005; McDaniel, Guynn, Einstein, \& Breneiser, 2004). For instance, Einstein et al. (2005) documented conditions where participant PM performance was high, yet this high PM performance came with no significant cost to ongoing task performance. Although McDaniel and Einstein, through their multiprocess theory, posit that there are multiple routes to a successful PM retrieval, other theorists argue that one process underlies all prospective remembering (Smith, 2003; Smith \& Bayen, 2004).

Smith (2003; Smith \& Bayen, 2004) proposed the preparatory attentional and memory processes (PAM) theory as an alternative to the multiprocess theory. Smith asserts that the engagement of "capacity-demanding preparatory attentional processes" (e.g., nonautomatic monitoring of the environment) is a prerequisite for prospective remembering, and that monitoring is always required for successful PM (Smith, 2003, p. 349). Since preparatory attentional processes are not automatic (i.e., monitoring of the environment), they place demands on cognitive resources, imposing a cost to ongoing task performance within PM tasks. The key distinction between the PAM and multiprocess theory is that according to PAM, there should 
always be costs to ongoing task performance with an embedded PM task, and this cost in performance reflects active monitoring.

In a series of studies, Smith has evidenced performance costs associated with a PM task (Smith, 2003; Smith, Hunt, McVay, \& McConnell, 2007). For example, Smith et al. (2007) asked participants to complete an ongoing lexical decision task in which the participant's name appeared as the PM cue. Thus, the cue was both focal (i.e., processing the name was part of the ongoing task) and salient (i.e., most people recognize their name in a divided attention task). Results indicated that ongoing task performance declined in the second block of the lexical decision task in which PM cues (participant names) appeared relative to that of the first lexical decision block which did not include a PM task. This pattern suggests that performance costs can emerge even with focal, salient, personally-relevant PM cues (i.e., one's own name). Additional studies offer further evidence that preparatory attentional processes (such as monitoring) can burden cognitive resources (Burgess, Quayle, \& Frith, 2001; Cohen, Jaudus, \& Gollwitzer, 2008; Smith \& Bayen, 2005). The debate continues regarding whether the deployment of capacitydemanding monitoring resources is a necessary requisite for the actualization of PM (Einstein \& McDaniel, 2010; Smith, 2010). Some theorists assert that monitoring is required in all circumstances to successfully retrieve an intention (PAM theory), while others posit that although certain situations call for monitoring, other situations allow for relatively spontaneous and rapid retrieval of intentions (multiprocess theory).

Neural Mechanisms of Prospective Memory. Although successful PM depends upon remembering the nature of one's intention, several additional executive functions play a key role in PM task execution. Consistent with a heavy reliance upon executive functions, the results of several neuroimaging studies suggest that frontal regions of the brain play a prominent role in 
prospective remembering. Specifically, the rostral prefrontal cortex (PFC), also called Brodmann area 10, appears to be vital to realizing intentions (Benoit, Gilbert, Frith, \& Burgess, 2012; Burgess et al., 2001; Burgess, Scott, \& Frith, 2003; Okuda et al., 2007; 1998; Simons, Schölvinck, Gilbert, Frith, \& Burgess, 2006). These neuroimaging findings also fit with the results of patient studies (Burgess et al., 2001; Burgess, Veitch, Costello, \& Shallice, 2000; Goldstein, Bernard, Fenwick, Burgess, \& McNeil, 1993; Shallice \& Burgess, 1991), and investigations of older adults characterized as possessing reduced frontal lobe function (McDaniel et al., 1999; McFarland \& Glisky, 2009).

In addition to prominent frontal activity, other imaging studies have revealed involvement of medial temporal lobe (MTL) structures, including the hippocampus, and posterior parietal regions. For example, Okuda et al. (2007; 1998), by use of Positron emission tomography (PET) techniques, revealed regional cerebral blood flow (rCBF) increases in the left anterior cingulate cortex (ACC; Brodmann Area 32), superior frontal gyrus (Brodmann Area 10), and parahippocampal gyrus (Brodmann Area 28), along with right hemisphere rCBF increases in the inferior and middle frontal gyri (Brodmann Areas 8, 9 and 47), and medial frontal lobe areas during a PM task. Similarly, Martin et al. (2007), using magnetoencephalography (MEG), observed activity in the frontal areas, posterior parietal areas, and the hippocampus. Gordon et al. (2011) supplemented these findings by evidencing significant positive correlations between the volumes of certain MTL structures and focal PM performance, such as hippocampal and parahippocampal volume (with the strongest correlation existing between the hippocampal volume and focal PM performance).

Other experimenters, by use of event-related potentials (ERPs), find that three modulators, the N300, the parietal old-new effect, and prospective positivity, consistently 
associate with the actualization of intentions (West, Bowry, \& Krompinger, 2006; West, Herndon, \& Crewdson, 2001; West, Herndon, \& Ross-Munroe, 2000; West \& Krompinger, 2005; West \& Ross-Munroe, 2002; West, 2007). The N300 links with cue detection, and the parietal old-new effect connects with the retrieval processes underlying recognition memory (West et al., 2001; 2000; West \& Krompinger, 2005; West \& Ross-Munroe, 2002). As for prospective positivity, previous work indicated that this modulator associates with the retrospective component of PM, or the retrieval of delayed intentions from memory (Bisiacchi, Schiff, Ciccola, \& Kliegel, 2009; West \& Ross-Munroe, 2002). However, the authors of a more recent study (see West \& Krompinger, 2005), suggest that prospective positivity may be more of a post-retrieval process, related to the coordination of prospective and ongoing task components after the retrieval of an intention (West et al., 2006).

In summary, the results of numerous studies have begun to converge on the brain regions involved in PM. Frontal lobe regions are of critical importance, especially the rostral PFC (Brodmann area 10), by providing frontally-supported executive functions thought to be necessary for successful PM (Burgess et al., 2001; Burgess et al., 2003; McFarland \& Glisky, 2009; Okuda et al., 2007; 1998; Simons et al., 2006). The MTL, along with its structures such as the hippocampus, may also contribute to prospective remembering through the development of associations between PM cue and intention, and retrieval of information from long-term memory (Gordon et al., 2011; McFarland \& Glisky, 2009; Okuda et al., 1998). Activation of parietal regions of the brain are associated with the noticing of target cues (or cue detection) and likely play a role in monitoring within a PM task (Burgess et al., 2001; Gordon et al., 2011; Martin et al., 2007). The anterior cingulate activation tends to co-occur with activation of frontal regions, suggesting that the interplay between these areas produce a cognitive control network, 
potentially responsible for the coordination of reflexive attention, as well as alertness to visual stimuli, and error detection (Burgess et al., 2001; Morishima, Okuda, \& Sakai, 2010; Okuda et al., 2007; 1998; Okuda, Gilbert, Burgess, Frith, \& Simons, 2011; Simons et al., 2006).

Electrophysiological data agree with the notion that these brain areas relate to PM performance as well. Modulators like the N300 (over the occipital-parietal and frontal brain regions), the parietal old-new effect (covering the parietal brain region), and prospective positivity (distributed over the central, parietal, and occipital regions of the brain) span many of the neural regions found by other experimenters to connect with PM (Paller \& Kutas, 1992; West et al., 2006; 2001; 2000; West \& Krompinger, 2005; West \& Ross-Munroe, 2002; West, 2007). The research base regarding the neural underpinnings of prospective remembering is expanding, and the agreement between functional neuroimaging studies, human lesion studies, and electrophysiological studies contributes greatly to understanding how these mechanisms relate to PM (Okuda et al., 2011).

To further advance the understanding of the neural basis of PM and to inform clinical interventions, the field has expanded to include studies of PM in a wide variety of clinical populations with known neuropsychological or neuroanatomical disruptions. For example, impairments in prospective remembering link with depression (Altgassen, Kliegel, \& Martin, 2009; Rude, Hertel, Jarrold, Covich, \& Hedlund, 1999), attention deficit hyperactivity disorder (ADHD; Kerns \& Price, 2001; Kliegel, Ropeter, \& Mackinlay, 2006), mild cognitive impairment (Costa, Caltagirone, \& Carlesimo, 2011; Costa, Carlesimo, \& Caltagirone, 2012; Tam, \& Schmitter-Edgecombe, 2013), and Parkinson's disease (Costa et al., 2012; Kliegel et al., 2011), among others. One topic that remains neglected in the literature, however, is the relation between 
stress and PM. Delineating the relations between stress and PM is critical, since stress is a phenomenon that everyone experiences (Asmundson \& Taylor, 2005; Baum, 1990).

\section{Stress}

The definition of stress varies greatly across the literature. However, most agree that stress involves a stressor and a physiological reaction to that stressor (or stress response). Stressors are the agents or events that evoke the stress response, and can be anything that challenges an organism's homeostasis (Cohen, Kessler, \& Gordon, 1997; Hoes, 1986; Lupien, Maheu, Tu, Fiocco, \& Schramek, 2007; Lupien et al., 2006; Selye, 1975; 1998). Lupien et al. (2007) distinguish between "absolute" stressors (real threats such as natural disasters) and "relative" stressors (implied threats such as public speaking tasks), that can bring organisms away from homeostatic states (p. 210). Due to the rarity of absolute stressors in the modern world, most of the stressors people encounter are relative stressors (Lupien et al., 2007; 2006). Examples of relative stressors include having too many assignments to handle at work, to interpersonal difficulties with a significant other, family, or friends, to presentations and public speaking tasks. Relative stressors necessitate cognitive interpretation or analysis, which may or may not lead to a physiological response (Lupien et al., 2007; 2006).

The cognitive analysis that might accompany facing a relative stressor ranges from interpreting the stressor as not stressful at all, to very stressful. For instance, some might consider giving a presentation in front of an audience to be a very stressful event, while for others the same situation evokes little stress (Lupien et al., 2007). The stress response is an adaptive physiological reaction to stressors on an organism, serving to return the organism back to equilibrium (Cohen et al., 1997; Hoes, 1986; Lupien et al., 2007; 2006; Selye, 1975; 1998). Physiological responses to stressors differentiate into acute stress, where a short-term stress 
response emerges in reaction to the presence of a stressor, and chronic stress, which is a more enduring stress response evoked by persistent stressors (Lupien et al., 2007; Shields, Sazma, \& Yonelinas, 2016; Timko, Moos, \& Michelson, 1993). When one encounters a stressor, a physiological process engages, wherein the hypothalamus-pituitary adrenal (HPA) axis activates, causing the periventricular nucleus of the hypothalamus to stimulate the secretion of corticotropin-releasing hormone $(\mathrm{CRH})$. The release of $\mathrm{CRH}$ activates secretion of adrenocorticotropin $(\mathrm{ACTH})$ from the pituitary gland, which then triggers the discharge of stress hormones (Belanoff, Gross, Yager, \& Schatzberg, 2001; Lupien et al., 2005; 2007; 2006; Marin, Pilgrim, \& Lupien, 2010).

Two categories of stress hormones release from the adrenal cortex in response to the chain reaction induced by a stressor. The catecholamines (adrenaline and noradrenaline) represent one such class of stress hormone, while glucocorticoids (GCs; called cortisol in humans) constitute the other (Belanoff et al., 2001; Ferris \& Stolberg, 2010; Lupien, 2009; Lupien et al., 2005; 2007; 2006; Wolf, 2009). Human basal cortisol secretion follows a 24-hour circadian rhythm, with baseline cortisol concentrations peaking in the morning (the circadian peak). Throughout the day, the baseline level of GCs slowly decreases during the late afternoon and evening, leading to a low level nocturnal period (the circadian trough), followed by a rapid rise of basal levels during the early hours of sleep (Lupien et al., 2007; 2002; Van Cauter \& Turek, 1994). The induction of GCs (above and beyond basal levels) has a wide range of effects on an organism, one of which may be to augment, or in some instances, reduce, certain cognitive faculties, such as learning and memory (Lupien et al., 2007; Qin, Hermans, van Marle, Luo, \& Fernandez, 2009; Roozendaal, 2002). 
Stress, Memory, and Executive Functions. The relation between stress and RM has garnered considerable research attention (Payne et al., 2007; Payne, Nadel, Allen, Thomas, \& Jacobs, 2002; Smeets, Otgaar, Candel, \& Wolf, 2008; Wolf, 2008), with investigators typically interested in either long-lasting, chronic stress, or short-term, acute stress (Het, Ramlow, \& Wolf, 2005; Wolf, 2008). Much of the research in this area suggests that chronic stress impairs performance on memory tasks (Het et al., 2005; Kirschbaum, Wolf, May, Wippich, \& Hellhammer, 1996; Payne et al., 2002; Wolf, 2003). On the other hand, investigations of the impact of acute stress on memory have produced equivocal results, with some identifying modulatory effects (Cahill, Lukasz, \& Kathryn, 2003; Marin et al., 2010; Payne et al., 2007; Smeets et al., 2008), while others reveal impairing effects (de Quervain et al., 2003; de Quervain, Roozendaal, Nitsch, McGaugh, \& Hock, 2000; Kirschbaum et al., 1996; Smeets et al., 2008).

Although the results have been somewhat mixed to date, whether stress has beneficial or deleterious effects on memory appears to rely on many factors, such as the memory type, at which memory phase the stress exposure occurs (i.e., at encoding, consolidation, or retrieval), the amount of circulating stress hormones, emotional valance of the memory content, time of day, and participant factors such as age and sex (de Quervain, Aerni, Schelling, \& Roozendaal, 2009; Het et al., 2005; Kuhlmann, \& Wolf, 2006; Lupien et al., 2005; 2007; 2002; Meeks, Rosnick, Blackhurst, \& Overton, 2014; Payne et al., 2007; 2006; Roozendaal, 2000; 2002; Roozendaal \& de Quervain, 2005; Smeets, Jelicic, \& Merckelbach, 2006; Wolf, 2009). One prevailing conceptualization of the relations between acute stress and RM performance is that they follow an inverted ' $U$ ' dose-response curve, similar to the Yerkes-Dodson law (1908). According to this view, memory facilitation occurs when GC levels are at the top of this inverted $\mathrm{U}$, whereas memory impairments occur when circulating GC levels are insufficient or excessive 
(de Kloet, Oitzl, \& Joels, 1999; Kofman, Meiran, Greenberg, Balas, \& Cohen, 2006; Lupien \& Lepage, 2001; Lupien \& McEwen, 1997; Lupien et al., 2002; Roozendaal, 2002).

This interpretation is consistent with the circadian rhythm of stress, with the induction of GCs potentially exhibiting negative effects in the morning, when baseline levels of the stress hormone is high, and possibly revealing positive effects in the evening, when basal concentrations are low (Het et al., 2005; Kirschbaum et al., 1996; Lupien, Gillin, \& Hauger, 1999; Lupien \& Lepage, 2001; Lupien et al., 2002). Lending support to the notion that stress may affect memory are studies showing that circulating stress hormones differentially influence the functioning of the brain structures involved with memory (Arnsten, 2009; Belanoff et al., 2001; Carver \& Cluver, 2009; Ferris \& Stolberg, 2010; Lupien et al., 2007). For example, the hippocampus contains high densities of GC receptor sites, and therefore, it is highly sensitive to the levels of circulating stress hormones (Belanoff et al., 2001; Carver, \& Cluver, 2009; Ferris \& Stolberg, 2010; Lupien \& McEwen, 1997; Lupien et al., 2007; Payne et al., 2002). Consequently, lasting stress can potentially lead to neuronal degeneration, inefficient glucose utilization, impaired synaptic proficiency, and decreased overall volume in this area (Ferris \& Stolberg, 2010; Lupien et al., 2005; Sapolsky, 2000).

Brunner and colleagues (2005) illustrate memory impairments, attributable to the administration of exogenous GCs, on declarative memory recall tasks that depend on hippocampal functioning. This finding is in line with the results of a PET study demonstrating that memory retrieval impairments due to GCs correlate with decreased activity of the MTL (de Quervain et al., 2003; Roozendaal \& de Quervain, 2005). Experimenters employing imaging techniques elucidate that the MTL mediates, at least in part, the effects of cortisol on memory retrieval (de Quervain et al., 2003; Oei, Everaerd, Elzinga, van Well, \& Bermond, 2006). While 
GCs can interfere with hippocampus-dependent memory retrieval, they can enable hippocampusrelated consolidation processes (Roozendaal, 2002; Roozendaal, Griffith, Buranday, de Quervain, \& McGaugh, 2003).

Like the hippocampus, the frontal lobes also contain high densities of GC receptors, which can result in regions of the frontal lobes being sensitive to the effects of prolonged stress exposure (Luethi, Meier, \& Sandi, 2009; Lupien et al., 2005; 1999; 2007; Payne et al., 2002). One such region, the PFC, plays a vital role in supporting executive functions, such as WM (Miller \& Cohen, 2001; Reising, 2014; Qin et al., 2009). Exposure to acute stress seems to diminish WM function, which is in concert with findings of PFC dysfunction by influence of circulating stress hormones (Arnsten, 2009; de Quervain et al., 2009; Lupien et al., 1999; Lupien \& Lepage, 2001; Arnsten, 2000; Qin et al., 2009). Consistent with this notion, Qin et al. (2009) demonstrate that acute psychological stress reduces WM-related activation in the dorsolateral PFC. Functional sensitivity to the exposure of GCs might be even greater for WM than declarative memory (Lupien et al., 1999; Young, Sahakian, Robbins, \& Cowen, 1999). How stress affects the PFC differs by subregion (Mika et al., 2012). For example, the ACC and orbitofrontal cortex show different functional activation and dendritic changes in response to stress (Dedovic, D’Aguiar, \& Pruessner, 2009; Liston et al., 2006; Lupien, 2009; Wang et al., 2007). Given the findings that circulating stress hormones impact frontal functioning and can diminish WM function, stress might also affect other executive functions that the PFC supports. Beyond knowledge of how stress impacts WM, surprisingly little research exists on the relations between stress and executive functions, and much of the research in this area focuses on how chronic stress, rather than acute stress, affects executive functions (Mika et al., 2012; Reising, 2014). Furthermore, of the extant literature on this topic, the results are mixed. For 
instance, investigators reveal beneficial (Chajut \& Algom, 2003), impairing (BraunsteinBercovitz, 2003; Keinan, Friedland, Kahneman, \& Roth, 1999), and neutral (Brand, Schneider, \& Arntz, 1995; Stawsky, 2007) effects of stress on selective attention. These mixed results concerning how stress affects selective attention may be, at least in part, due to heterogeneity in the methods used to induce stress, as well as differences in the tasks used to measure selective attention (Braunstein-Bercovitz, 2003; Skosnik, Chatterton Jr., Swisher, \& Park, 2000; Stawsky, 2007). The influence of stress seems to be more directionally-specific in relation to other executive functions. For example, Kofman et al. (2006) reveal facilitatory effects of examination stress on two executive function tasks, the first task being performance on a task-switching paradigm, and the second being reduction of reaction times in the Stroop task (inhibition). This was the first study to reveal performance-enhancing effects of stress on these executive functions (Kofman et al., 2006). Since the relationship between stress and executive function is, at present, relatively convoluted, this area requires additional research.

Developing an understanding of how stress affects the brain regions that mediate memory processes, as well as how stress influences executive functions, may provide indirect indications of how stress affects other phenomena, such as PM. Although conclusions from research concerning the influence of stress on executive functions may be difficult to interpret with confidence at this time, when taken together with data on how stress impacts the brain regions involved with memory, one may derive a better understanding. As described above, stress affects brain regions that are involved in various forms of memory, as well as executive functions. To illuminate how stress affects these cognitive and neural processes, experimenters employ various methodologies to evoke stress. The Trier Social Stress Test (TSST; Kirschbaum, Pirke, \& Hellhammer, 1993) is the most commonly used paradigm for studying the effects of stress. 
The Trier Social Stress Test. The TSST is a widely-accepted paradigm for inducing acute stress, and has high reported reliability and effect sizes (Kirschbaum et al., 1993; Payne et al., 2007; von Dawans, Kirschbaum, \& Heinrichs, 2011). The original TSST protocol includes a brief public speaking task followed by a mental arithmetic task performed out loud in front of a panel of strangers (von Dawans et al., 2011). Kudielka, Hellhammer, and Kirschbaum (2007), through a review of a decade of research with the TSST on clinical and non-clinical populations, provide an up-to-date description of the TSST. Under the updated protocol of the stress induction paradigm, the TSST is a motivated performance task which first entails a brief period for preparation (approximately three minutes), followed by a public speech (approximately five minutes), and lastly, a mental arithmetic task (approximately five minutes), bringing the total time of the TSST administration to around 13 minutes. A rest period should precede the protocol to minimize prior stressful events or other confounding factors. Despite how time of day influences stress due to the circadian rhythm activity of the HPA axis, the authors posit that net cortisol elevations after exposure to the protocol can be reliably assessed equally in the morning or afternoon (Kudielka et al., 2007; Kudielka, Schommer, Hellhammer, \& Kirschbaum, 2004).

Kelly, Matheson, Martinez, Merali, and Anisman (2007) utilized a modified version of the TSST to determine if participants who undergo the TSST in front of a virtual audience (by use of virtual reality) elicit elevated cortisol levels when compared to non-stressed participants. In addition, they compared the cortisol level elevations found in those performing in the TSST in front of a virtual audience to those performing in the TSST in front of an imaginary audience behind a one-way mirror, and a real audience sitting in the same room. Not surprisingly, the authors found that those who performed in the TSST displayed elevated cortisol levels. However, those who performed in the TSST in front of a real audience had the highest rise of 
cortisol levels (90\% above baseline), followed by those who performed in the TSST in front of a virtual audience (about $30 \%$ above baseline) and the imagined audience ( $20 \%$ above baseline). Despite differences in the cortisol levels between groups, those who participated in the TSST exhibited elevated GC levels when compared to controls (Kelly et al., 2007).

Payne et al. (2002) had participants perform the modified version of the TSST, with participants delivering the speech in front of a one-way mirror (behind which they believed to be three trained investigators) to examine the effects of induced stress on false memories. Despite utilization of the modified TSST, the authors found that acute stress significantly increased one type of false memory, or the false recognition of semantically-related words not presented in the study (Payne et al., 2002). These studies indicate that the TSST has more than one method of implementation by which reliable facilitation of GC level elevations is possible. Since the TSST is a public speaking task coupled with a mental arithmetic task, Lupien and colleagues (2007) classify this type of stressor as a relative stressor. Whether original or modified, the TSST shows dependable facilitation of the release of GCs (Kelly et al., 2007; Nater et al., 2006; Payne et al., 2002; 2007; von Dawans et al., 2011). Therefore, researchers frequently employ this paradigm to test the effects of stress on various processes, such as memory.

\section{Stress and Prospective Memory}

To date, only eight studies compose the literature documenting the relations between stress and PM (Eskildsen et al., 2015; Glienke \& Piefke, 2016; Ihle et al., 2014; Ihle, Schnitzspahn, Rendell, Luong, \& Kliegel, 2012; Nakayama, Takahashi, \& Radford, 2005; Nater et al., 2006; Schnitzspahn, Ihle, Henry, Rendell, \& Kliegel, 2011; Walser, Fischer, Goschke, Kirschbaum, \& Plessow, 2013). Further, these studies differ by whether they measure PM in the context of baseline stress (Nakayama et al., 2005), acute stress (Glienke \& Piefke, 2016; Ihle et 
al., 2014; Nater et al., 2006; Walser et al., 2016), or chronic stress (Eskildsen et al., 2015; Ihle et al., 2012; Schnitzspahn et al., 2011), and whether they are laboratory-based or naturalistic in nature. Although the literature in the area is still in its infancy, the small number of studies begin to converge on the potential conditions in which stress might influence PM.

Nakayama and colleagues (2005) were the first to investigate how stress (cortisol levels) relates to PM. Through use of a memory task that measured both PM and RM, and by measuring baseline cortisol levels, they discovered that although a significant association existed between salivary cortisol levels and RM, no such relation existed between salivary cortisol levels and PM. Nevertheless, several experimental procedures limited the study. The first limitation is that the researchers did not investigate both event-based and time-based PM, but limited their investigation to only event-based PM. This drawback is important because the literature clearly differentiates between two forms of PM, of which time-based PM likely requires more selfinitiated processing, and thus may be more sensitive to the effects of circulating stress hormones. The second limitation is that the authors measured only baseline cortisol levels, rather than directly test the effects of GCs on PM (Nater et al., 2006). Lastly, the sample was composed of only 34 male students, which prevented possible analysis of the intersection between stress, PM, and participant sex. For example, perhaps GC induction impacts PM for males differently than for females, given that stress may affect males and females differently (Kirschbaum, Kudielka, Gaab, Schommer, \& Hellhammer, 1999).

Acute Stress Manipulations and PM. Nater et al. (2006) furthered research in this area by examining if induced psychosocial acute stress affected both event-based and time-based PM. This study included a within-subjects design, where 20 male participants performed in both the experimental condition (TSST) and control condition (resting), with a randomized and 
counterbalanced order of condition over a two-week period. The authors measured salivary samples of GC levels 20 minutes before the TSST, right before the TSST, immediately after TSST completion, and 15, 30, 45, and 60 minutes after TSST completion. The PM paradigm used in the study, introduced by Einstein et al. (1997), entailed a computerized word rating task also containing measures for both event-based PM (measured by pressing a target key after a target word appears) and time-based PM (measured by pressing a target key every two minutes). The authors demonstrated that acute psychosocial stress enhanced time-based PM in young men, though they did not find a stress effect for event-based PM in this study. These results were like the findings of Nakayama et al. (2005) by illustrating a lack of a significant relation between stress and event-based PM. However, this study revealed that stress can facilitate time-based PM performance (Nater et al., 2006). It is important to note, however, that these authors also limited their study to a small sample of male participants (20 healthy males).

More recently, Walser et al. (2013) employed the TSST to investigate how stress induction influences the ability to realize intentions. Further, they included both males and females in the study to document possible sex-effects. The testing took place in the afternoon to avoid the cortisol awakening response (the circadian peak). Within this study, the ongoing task for each block consisted of 24 trials of animate-inanimate categorization. Trials began with a fixation sign, followed by presentation of a target word until participants responded. In the PM block, participants were to press the spacebar upon encountering two specific PM target cues (the words "candle" and "eagle"). They measured only event-based PM directly, but also tracked changes in monitoring behavior to determine if a strategic shift takes place under conditions of acute stress, which may have accounted for the enhanced time-based PM performance found by Nater et al. (2006). In the test block, participants completed the animate-inanimate categorization 
on all trials. A cycle entailed a PM block and a test block, in which assessment of completed intentions took place. Participants underwent "extensive training" for the cognitive task (consisting of training participants on three cycles of a PM block and test block), which preceded the stress/no stress treatment (p. 4). The experimental cognitive task took place after 10 to 50 minutes after stress cessation. During each cycle, researchers presented 11 random animate and inanimate words four times each throughout the PM and test blocks, leading to a total number of 88 trials per block.

The results of the study suggested that although the participants exposed to the TSST exhibited reliable biological stress responses (i.e., elevated levels of salivary cortisol), stress induction did not significantly impact PM performance, ongoing task performance, or aftereffects of completed intentions. Additionally, preservation of the ability to realize intentions under stress conditions occurred for both men and women, indicating that the effects of stress (or lack thereof) on PM may not differ by participant sex. These results were striking, given the potentially depleting effects of stress on cognitive resources (Steinhauser, Maier, \& Hübner, 2007), and how stress affects brain functioning and cognitive abilities, such as executive functions. Walser et al. (2013) stated that monitoring costs were equal between the treatment groups, indicating there may not have been a strategic shift in resources for PM retrieval (i.e., monitoring-based intention retrieval versus spontaneous intention retrieval) for participants who were in the stressed group. However, by employing focal cues within the study, as well as extensive training in PM blocks, the simplicity of the event-based task (and ongoing task) may have obviated the need for the type of high processing demands that stress impacts. PM tasks that are more complex may require additional cognitive resources and self-initiated processing, and therefore, might be more sensitive to the effects of acute stress (Walser et al., 2013). 
Ihle et al. (2014) investigated the role of stress in age-related PM impairments within laboratory settings. One of the goals of the study was to determine whether higher levels of stress, particularly for older adults, contributes to the differences in PM performance found between younger and older adults. In the study, half of the participants completed stressreduction techniques, such as progressive muscle relaxation and autogenic training, while the other half read text. After these tasks, participants completed a 2-back WM task with an embedded time-based PM task, where they were to remember to press the "V" key after every minute. Notably, their analyses revealed that higher levels of baseline stress at the outset of the study was associated with enhanced time-based PM and monitoring behavior overall, and among older adults. Heart rate also connected with older adult time monitoring. Yet, after participants engaged in stress reduction procedures, stress levels and heart rate had no significant association with time-based PM performance, monitoring, or ongoing task performance (Ihle et al., 2014).

Glienke and Piefke (2016) conducted the most recent study examining the relations between acute stress and PM. In their experiment, they randomized 49 male participants to either a control or stress group. To induce acute stress responses among participants, those in the experimental group completed the Socially Evaluated Cold Presser Test (SECPT; Schwabe, Haddad, \& Schachinger, 2008), in which participants placed their left hand in cold water for three minutes while simultaneously being videotaped and observed directly by an experimenter. The authors collected salivary cortisol samples to track changes in stress levels throughout the study. Participants completed the PM paradigm after their respective group tasks. Their PM measure, the "Plan a Holiday" task, entailed planning, memorizing, and retrieving/executing intentions throughout a virtual holiday week. The first stage of the task involved planning and memorizing events (i.e., the planning phase of PM) occurring on Monday, Tuesday, Wednesday, 
and Thursday. These events were both time-based and event-based. After the planning phase of the task, participants underwent a 40-minute retention phase, within which they included a 10minute sustained-attention task as a distractor (Glienke \& Piefke, 2016).

The last phase of the task involved implementing the fictional holiday week. During this phase, participants carried out time- and event-based PM events throughout the four-day holiday week. Comparison of group performance across the task indicated that initial stress induction before the planning phase did not contribute to significant performance differences in planning performance and abilities. However, during the later retrieval/execution phase of the task, those who underwent stress induction procedures maintained stable PM performance over the task week, whereas the PM performance among those in the control group decreased over the same course. The PM enhancement occurred for general PM, time-based PM, and event-based PM, with the most robust increases in prospective remembering emerging later in the week (Glienke $\&$ Piefke, 2016). The authors attributed the stability in PM performance among those in the experimental group largely to acute stress induction during the planning phase of the task, such that acute stress conditions might modulate the encoding of intentions, as well as combat one's susceptibility to the primacy effect.

Glienke and Piefke (2016) concluded that acute stress induction may augment memorization of intentions, thus enabling increased likelihood of intention retrieval/execution during the appropriate time or circumstance. The authors also acknowledged that other factors at play may have contributed to the observed findings. For instance, they noted that the high task complexity may have enabled the sensitivity to detect changes in executive functions and attentional capacities due to acute stress induction. Further, providing financial incentives for 
good PM performance may have altered participant motivation, as well as the interaction between stress and reward expectation (Glienke \& Piefke, 2016).

Chronic Stress and PM. Schnitzspahn and colleagues (2011), while exploring possible mechanisms of the age-related paradox (i.e., age-related deficits in laboratory-based PM performance and age-related benefits in naturalistic PM tasks), suggested that everyday stress may play an important role in this paradox. They believed stress to relate to ongoing task absorption, such that stress may influence one's absorption in an ongoing task, in turn impacting PM performance. More specifically, the differences between older and younger adult daily stressors (e.g., retirement lifestyle versus activities that potentially carry more stressors, such as work and school) might create differences in the amount of cognitive resources available to dedicate to forming and carrying out PM strategies. The authors quantified stress through subjective measures, and asked participants to complete laboratory and naturalistic PM tasks. Their analyses revealed that ongoing task absorption, as assessed by stress ratings, eliminated the age effect when added as a covariate. Although they could not disentangle stress from the other processes that may affect one's ongoing task absorption, they identified stress as a potential factor underlying the age-related paradox (Schnitzspahn et al., 2011).

To further examine the role of everyday stress in age-related PM performance, Ihle et al. (2012) conducted a naturalistic study investigating how everyday stress (and other factors) influences one's ability to realize future intentions (both event-based and time-based). Naturalistic PM performance quantification occurred through telephone interviews, where experimenters called participants each day to collect data on the intentions that participants planned to complete, and in turn whether they had completed these planned intentions. They also measured everyday stress in these daily phone calls by utilizing a zero (no stress) to ten (very 
stressed) subjective rating scale, and created a global stress value by averaging the scores over the course of the study. The authors then evaluated PM performance in the context of everyday stress to identify whether stress emerged as a factor underlying age differences in everyday PM. They demonstrated that although there were no significant age differences in everyday stress levels, after entering everyday stress in hierarchical analysis, they found a significant main effect of everyday stress on PM performance. Additionally, they found a significant negative correlation between everyday stress and PM performance for the overall sample $(r=-0.36)$, leading the authors to conclude that everyday stress was a "detrimental factor" to PM performance (Ihle et al., 2012, p. 97). These findings echoed the results of the study by Schnitzspahn et al. (2011).

Eskildsen et al. (2015) also documented similar findings when investigating the relations between work-related stress and cognitive functions. One of their goals was to measure putative cognitive impairments, resulting from chronic stress, by use of neuropsychological testing. The participants recruited for this study were 49 outpatients with work-related stress. To quantify chronic stress, the researchers utilized interviews assessing stress symptoms and the 10-item Perceived Stress Scale (PSS10; Cohen, Kamarck, \& Mermelstein, 1983). After measuring stress, the authors then administered a neuropsychological test battery to participants that included indexes of processing speed, WM, general and immediate memory, PM, and other domains. Prospective memory quantification occurred through use of a self-made PM task, in which participants were to remember to give the experimenter a piece of candy after each task, with a maximum score of 18. Upon analyzing performance on these neuropsychological measures in the context of chronic stress, they discovered that three cognitive impairments stood out as statistically significant: PM, processing speed, and performance on The Paced Auditory Serial 
Addition Test (PASAT), which taps into WM, arithmetic, speed, as well as aspects of attentional processing (e.g., sustained attention).

The results provided by Eskildsen et al. (2015) are in concert with the small number of studies examining the influence of chronic stress on PM performance, such that chronic stress impaired one's ability to complete intentions in the future. Further, the discovery that participants with higher levels of chronic stress also exhibited impairments in executive functions, such as attentional processes that might be necessary for successful PM (Smith, 2003; Smith \& Bayen, 2004), supplement this finding. Yet, it is important to note that the PM measure used for the study was self-made and not validated (Eskildsen et al., 2015). This measure also assessed only event-based PM, rather than both event- and time-based PM. Despite these limitations, their results contribute to sparse literature base on the topic, and further suggest that chronic stress might be an impairing factor to PM performance.

Summary of the Literature on Stress and PM. Although the previously described studies provide somewhat mixed results, there appears to be an emerging picture regarding the impact of stress on PM. Specifically, stress might differ as to the way it influences PM performance depending on the type of stress (i.e., acute or chronic). Research examining the impact of short-term acute stress on PM performance reveal either no influence (Ihle et al., 2014; Walser et al., 2013) or associated PM performance benefits while under conditions of acute stress (Nater et al., 2006), with some of those benefits potentially enduring over longer periods of time (Glienke \& Piefke, 2016). It appears that under some circumstances, acute stress has the potential to enhance one's ability to complete intentions in the future. On the other hand, research investigating the relations between long-term, chronic stress and PM demonstrate largely that chronic stress can impair PM performance (Eskildsen et al., 2015; Ihle et al., 2012; 
Schnitzspahn et al., 2011). Yet, Ihle et al. (2014) discovered that perceived stress at the outset of the study associated with enhanced time-based PM and monitoring behavior, which might tap into chronic stress that participants brought into the study. Overall, the research base surrounding the relations between stress and PM is still in its infancy, which makes it difficult to specify the exact relations between stress and PM. Despite recent interest in this area, even the most basic questions remain unanswered at this time. Although the extant literature provides little clarity regarding relation between stress and PM, knowledge of how stress affects RM and executive functioning may provide further indication as to how stress may differentially impact PM.

\section{Objectives and Hypotheses}

The objective of the present study is to further explore the relations between stress and PM. Specifically, we designed this study to further document the relations between stress and time-based PM, and to investigate how stress impacts non-focal event-based PM for the first time, in a laboratory setting. We hypothesized that there would be a statistically significant difference between the experimental group (stressed group) and the control group (non-stressed group) on time-based PM task performance, such that those in the stressed group would have significantly higher scores on the time-based PM task when compared to those in the nonstressed group. In addition, we hypothesized that there would be a statistically significant difference between the experimental group (stressed group) and the control group (non-stressed group) on non-focal event-based PM task performance, with those in the stressed group

producing significantly higher scores on the non-focal event-based PM task when compared to those in the non-stressed group. 


\section{Method}

\section{Participants}

Participants were recruited through the psychology pool at the University of Montana (IRB \# 5-16). Participants were ineligible for the study if they were under the age of 18, over the age of 40 , received a previous or current diagnosis of a neurological condition, had a history of a traumatic brain injury, or received a previous diagnosis of attention-deficit/hyperactivity disorder (ADHD). Participants received research credit for their introduction to psychology course upon completion of the study. A total of 86 participants completed the study, with a participant mean age of 21.23 years. However, due to technical difficulties, data for six participants was not recorded, resulting in a total number of 80 for analysis ( 40 per group). Of the total sample, 26 identified as male, 55 as female, two as other, and three participants did not provide data on gender identity. In terms of college education, 43 were freshman, 23 were sophomores, eight were juniors, six were seniors, two identified having six or more years of college, one endorsed the option "not applicable," and three participants did not provide information on college education. The average years of education after high school was 1.89 years. Regarding ethnicity, 72 identified as Caucasian, four identified as Hispanic/Chicano, one identified as African American, two identified as Native American, one identified as Asian American, three identified as mixed ethnicity, and three participants did not provide data on ethnic identity. These sample demographics, with the exception of age, approximate the Montana State Census (2010) population demographics.

\section{Measurement and Instrumentation}

Demographics, Inclusion Criteria, and Perceived Global Stress. A standard demographics questionnaire included questions about participant age, biological sex, gender 
identity, current year in college, and ethnicity/race. Additionally, the questionnaire included questions regarding the exclusion criteria, asking if they were between the ages of 18-40, had a diagnosis of ADHD, any neurological condition, or had experienced an accident in which they became unconscious for over 30 minutes, and if they had received a diagnosis for any other psychological disorder. The questionnaire also included inquiries about perceived global stress, or the self-reported stress levels that participants experienced within the last week (e.g., "On a scale of $0-10$, with 0 indicating no stress, and 10 indicating the most stress you have ever experienced, how stressed out have you been over the past week?"). This scale measured everyday stress similarly to the paradigm included in the studies by Ihle et al. (2012) and Schnitzspahn et al. (2011).

Positive And Negative Affect Schedule (PANAS). All participants completed two administrations of the Positive and Negative Affect Schedule (PANAS; Watson, Clark, \& Tellegen, 1988), a widely-used measure of affective states, to assess momentary subjective stress levels of participants before and after the TSST and word search activity. The Centre for Studies on Human Stress (CSHS) lists the PANAS as a questionnaire used frequently to study environmental and psychosocial stress (Echterhoff \& Wolf, 2012; Qin et al., 2009). PANAS scores, particularly the negative affect (NA) subscale, reflect stress levels, and correlate with circulating glucocorticoid concentrations (Merz \& Roesch, 2011; Polk, Cohen, Doyle, Skoner, \& Kirschbaum, 2005; Qin et al., 2009). Reliability estimates for the PA and the NA scales were measured using Cronbach's alpha, with the reliability estimate for PA being .89, and the reliability estimate for NA being .85 (Crawford \& Henry, 2004). 


\section{Procedure}

Data collection took place in the afternoon to avoid testing participants during the circadian peak of the stress cycle (Lupien et al., 2007; 2002). To begin, participants received a detailed description of the study, including the fact that some portions of the study might be uncomfortable. The researchers explicitly informed participants that they could withdraw from the study at any time, and then asked participants to sign an informed consent. We then randomly assigned participants to either the experimental group (condition 1) or control group (condition 2) by assigning them to alternating groups as they came into the study. Next, participants completed the demographic, exclusion criteria, and everyday stress questionnaire. Upon completion of these instruments, participants in both groups received verbal instructions for the PM task that they were to complete later in the study (forming a PM intention). The instructions were as follows:

"Later in this study you will complete a trivia task that is designed to test your knowledge. In this trivia task, you will answer a series of multiple-choice trivia questions, and you will have 12 seconds to answer each question. Try to answer them as quickly and accurately as possible. At the same time, we are also interested in your ability to complete two other tasks. For the first additional task, press the "left shift" key when you come across a specific target word. This target word is the word "can." You will only come across this word in the context of another word. For example, in a trivia question, if you come across the word "candle," you would press the "left shift" key because this word contains the target word "can." This target word could be present at beginning of a word, the middle of a word, or the end of a word. For the second additional task, press the "right shift" key on the keyboard after every four minutes have elapsed since the start of the task. When you start the task, a timer will keep track of your total 
time. You may press the "enter" key on the keyboard to display this time. For example, once four minutes, eight minutes, twelve minutes, etc., elapses on the clock, you will press the "right shift" button on the keyboard. Do you have any questions? These instructions will not be repeated later in the study."

After administering the instructions for the PM task, researchers asked the participants questions about the task to ensure that they understood the instructions. For example, participants needed to answer questions such as, "When you come across the word "can," what do you do?," "what do you do after every four minutes have elapsed since the start?," and "how do you display the timer that shows the elapsed time on the computer?" If a participant answered one of these questions incorrectly, then the researcher repeated the instructions for that portion of the task. Once participants could successfully answer all the questions about the PM task, they completed the PANAS to provide information on their baseline levels of momentary stress. Upon completion of the measure, they completed their group-dependent tasks. Those in the control group completed a word search activity taken from the Memory for Intentions Screening Test (MIST; Raskin, 2004) to combat demand characteristics (i.e., participants continuously rehearsing the PM task), which would have created an unrealistic PM scenario (Einstein \& McDaniel, 1990). The word search activity lasted 13 minutes (timed on a digital timer), and after this period, participants in the control group completed the PANAS again. After the word search and completion of the PANAS, participants in the control group completed the PM task.

Researchers administered a stress protocol to those in the experimental group after they completed the demographic information, exclusion criteria, everyday stress questionnaire, instructions for the PM task, the learning check, and baseline PANAS measure. To elicit stress, participants completed a modified version of the TSST. To begin the TSST, researchers led 
participants into a room with a one-way mirror. Participants then received instructions for the TSST per the script provided by Birkett (2011). Researchers read the following script: "This is the speech preparation portion of the task; you are to mentally prepare a five-minute speech describing why you would be a good candidate for your ideal job. Your speech will be videotaped and reviewed by a panel of judges trained in public speaking. You have three minutes to prepare and your time begins now." After the three-minute preparatory period (timed by a digital timer), researchers then informed the participants that they were not able to use notes during the presentation, and that the participants were to give their notes to the researcher before they start their presentation. Upon collecting the notes, participants entered the speech portion of the task.

Researchers read the following script to start the speech section of the TSST: "This is the speech portion of the task. You are to deliver a speech describing why you would be a good candidate for your ideal job. You should speak for the entire the five-minute time period. Your time begins now." At that point, the researcher turned on a prop camera and spotlight that pointed towards participants as they presented. The researchers then left the room to observe the participants giving their presentation from the other side of the one-way mirror. Researchers could hear what participants were saying through a microphone that fed through a hole in the wall to the next room, to identify if the participant was engaging with the speech task. If a participant ceased talking for 20 seconds, the researcher prompted further presentation by going back to the room and saying to the participants that "you still have time remaining." Upon completion of the five-minute speech portion (as timed by a digital timer), the researcher informed the participant that the speech was over. 
The concluding section of the TSST was the mental arithmetic task. To begin, researchers read the following script to participants: "During the final five-minute math portion of this task, you will be asked to sequentially subtract the number 13 from 1,022. You will verbally report your answers aloud, and be asked to start over from 1,022 if a mistake is made. Your time begins now." The researcher then left the room to continue observation of the participant behind the one-way mirror. Researchers had a list of correct answers with them that they used to identify if participants gave a correct or incorrect response. If a participant provided an incorrect answer, then the researcher went into the room and told participants, "that is incorrect, please start over from 1,022." The task lasted for five minutes, as measured by a digital timer. After the TSST, participants again filled out the PANAS to measure changes in stress levels. They then completed the PM task. Salivary glucocorticoid levels were not measured, since the TSST paradigm reliably facilitates the induction of GCs (Kelly et al., 2007; Nater et al., 2006; Payne et al., 2002; 2007; von Dawans et al., 2011; Walser et al., 2013). No participants withdrew from the study due to excessive levels of anxiety, but one participant, after reading the informed consent, did not wish to participate after discovering the potential of being asked to present a speech. After participants in both the control and experimental group finished the PM task, the researchers debriefed them about the study, and provided them with research credit.

PM Paradigm. Participants received instructions for the PM task at the outset of the study to create the PM intention for execution in the future. The PM task itself was a multiplechoice trivia task (which served as the ongoing task), and participants had 12 seconds to respond to each question. The target word (the non-focal cue "can") appeared within the trivia questions after every 20 completed trivia questions. Upon encountering the event-based PM cue, participants needed to press the left shift key on the keyboard. For instance, upon encountering 
the word "Canada" in a trivia question, the participant then would press the left shift key on the keyboard if successful PM cue recognition took place. This PM task measured non-focal eventbased PM performance. Participants provided a successful event-based PM response when they pressed the left shift key while the trivia question containing the target word remained displayed.

In addition, participants were to press the right shift key on the keyboard after a certain time interval elapsed on a digital clock provided on the monitor (e.g., pressing the right shift key after every four minutes since the onset of the task). This served as the time-based PM task. Successful time-based PM responses depended on whether they pressed the right shift key within a 15-second window of the specific target time (i.e., 15 seconds before or after every four minutes elapsed). The PM task lasted 26 minutes in total, and data collection took place at six different intervals for the time-based PM task (once every 4 minutes). For the event-based PM task, six data points served as a measure of event-based PM task performance for each participant (the target word "can" appeared six times throughout the task). Other variables of interest measured included the number of clock checks, and the number of trivia questions answered correctly (i.e., ongoing task performance).

\section{Results}

Overall, the analyses demonstrated that our stress induction paradigm produced the expected increase in self-reported stress. Specifically, an independent samples $t$-test demonstrated that there were no significant mean differences in momentary stress levels between the experimental and control groups during the first PANAS assessment, $t(78)=1.148, p=.255$, $d=.261$. Critically, however, an independent samples $t$-test revealed a significant difference between groups on subsequent PANAS scores after experimental stress induction, $t(78)=5.574$, $p<.001, d=1.258$. Further, among those in the experimental group, a paired samples $t$-test 
showed significant elevations in the mean negative affect (NA) scale of the PANAS, thought to be most indicative of stress (negative emotionality) in this measure, when comparing PANAS scores from before $(M=15.70, S D=4.10)$ and after $(M=19.85, S D=6.59)$ the TSST, $t(39)=-$ $3.35, p<.001, d=.765$. Additional paired samples $t$-tests indicated that there was no such increase among control group participants, but rather a significant decrease in NA scores before $(M=14.65, S D=3.51)$ and after $(M=13.32, S D=3.24)$ the word search activity, $t(39)=2.693$, $p=.011, d=.446$. It is likely that these participants became accustomed to the requirements of the study, which may have led to reductions in acute stress levels. Individuals who underwent stress induction procedures also had significant mean reductions in positive affect pre $(M=$ 28.88, $S D=7.88)$ to post $(M=25.33, S D=8.37)$ stress induction, $t(39)=1.97, p<.001, d=$ .579. Those in the control group did not report significant elevations or reductions the PA component of the PANAS before $(M=26.70, S D=7.39)$ or after $(M=26.32, S D=8.28)$ the word search activity, $t(39)=.453, p=.654, d=.073($ see table 1$)$.

Table 1

Participant PANAS Scores Before and After Group Tasks

\begin{tabular}{lccccccc}
\hline Variable/Group & $N$ & $M-$ Pre & $S D$ & $M-$ Post & $S D$ & Sig Pre-Post & $d$ \\
\hline Negative Affect (NA) & & & & & & & \\
$\quad$ Stress & 40 & 15.70 & 4.10 & 19.85 & 6.59 & $p<.001$ & .765 \\
$\quad$ Control & 40 & 14.65 & 3.51 & 13.32 & 3.24 & $p=.011$ & .446 \\
Positive Affect (PA) & & & & & & & \\
$\quad$ Stress & 40 & 28.88 & 7.88 & 25.33 & 8.37 & $p<.001$ & .579 \\
$\quad$ Control & 40 & 26.70 & 7.39 & 26.32 & 8.28 & $p=.654$ & .073 \\
\hline
\end{tabular}


Regarding PM performance, independent samples $t$-tests comparing participants in the experimental and control groups revealed no significant group differences on PM performance due to acute stress induction. The analyses showed no significant group differences in Non-focal event-based PM performance between groups, $t(78)=-.650, p=.518, d=.179$. Similarly, the analyses demonstrated no significant group differences in time-based PM performance $t(78)=$ $.425, p=.672, d=.096$. (see table 2 and figure 1$)$.

Table 2

Prospective Memory Performance and Clock Checking Between Groups

\begin{tabular}{llll}
\hline Variable/Group & $N$ & $M$ & $S D$
\end{tabular}

Non-focal Event-Based PM Performance

$\begin{array}{llll}\text { Stress } & 40 & 1.55 & 1.47 \\ \text { Control } & 40 & 1.78 & 1.51\end{array}$

Time-Based PM Performance

$\begin{array}{llll}\text { Stress } & 40 & 3.74 & 2.32 \\ \text { Control } & 40 & 3.94 & 1.84\end{array}$

Clock Checking

Stress

$\begin{array}{lll}40 & 20.59 & 15.78\end{array}$

Control

$\begin{array}{lll}40 & 18.82 & 10.17\end{array}$

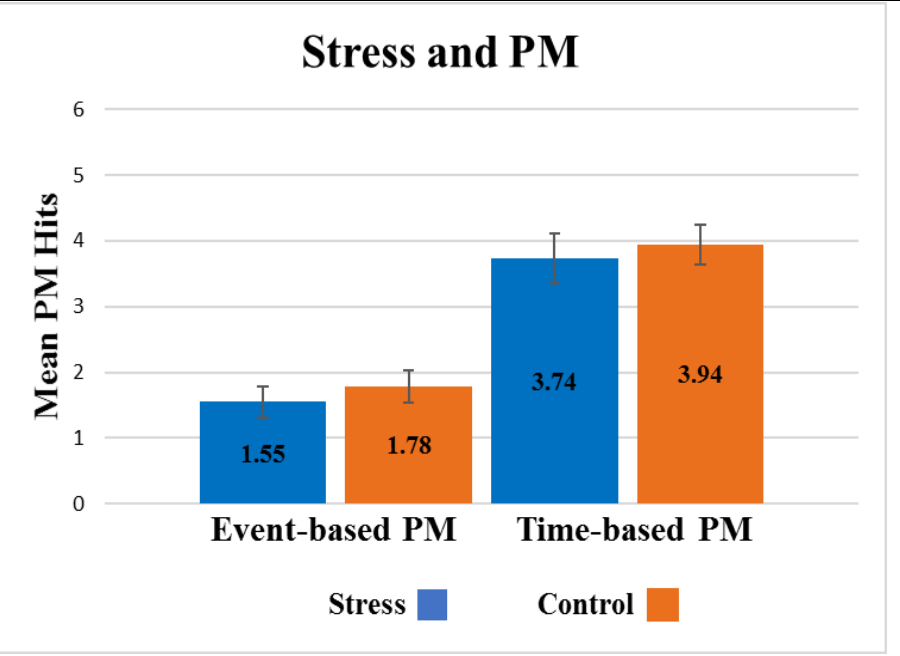

Figure 1. Mean number of (non-focal) event-based PM and time-based PM hits 
In light of our somewhat surprising findings that stress was not related to PM performance, we decided to split the task in two halves to determine whether the time course of the stress response may have contributed to our lack of significant findings. For example, it is possible that the peak of the stress response (approximately 15-20 minutes after induction), occurred later in the course of the PM task, whereby it would have had little impact on PM performance. There were no significant differences in PM performance, in either event- or timebased tasks, between the first and last half, $t$ 's $<1.02, p$ 's $>.32$, suggesting that our lack of significant findings between stress and PM was likely not due to a timing issue.

Despite the lack of significant findings between acute stress and PM performance overall, exploratory analyses revealed an association between acute stress and non-focal event-based PM among those participants who endorsed the highest levels of acute stress following the induction. That is, a strong positive correlation between acute stress and non-focal event-based PM, $r(6)=$ $.840, \mathrm{p}=.009$, emerged among those participants with the most elevated acute stress (i.e., NA scores above 25), indicating that when acute stress levels passed this point, there was a strong positive relationship between NA scores and non-focal event-based PM task performance. Analyses also revealed that perceived global stress (i.e., chronic stress) reported at the outset of the study correlated positively with time-based PM performance, such that higher levels of reported stress associated with better time-based PM performance, $r(78)=.293, \mathrm{p}=.011$. Higher self-reported global stress was also positively correlated with clock-checking behavior, $r(78)=$ $.233, p=.046$, regardless of group (see figure 2). Perceived stress did not correlate significantly with non-focal event-based PM performance, $r(78)=.089, \mathrm{p}=.451$. 


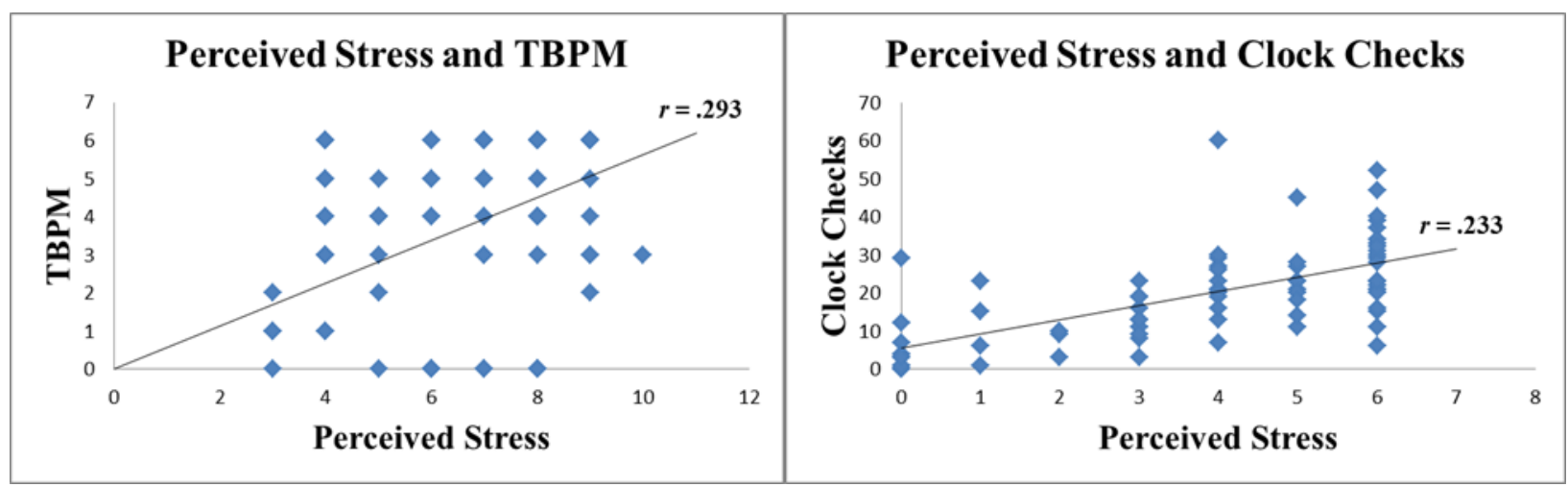

Figure 2. Correlations between perceived stress and TBPM (time-based PM), and perceived stress and clock checks.

Additional analyses revealed that clock checking, an indicator of monitoring behavior, was significantly correlated with time-based PM performance, $r(78)=.616, \mathrm{p}<.001$, regardless of group. Also, independent samples $t$-tests showed that there were no significant mean differences in clock checking behavior, $t(78)=0.834, p=.407, d=.136$, the number of correct responses to trivia questions, $t(78)=-1.421, p=.160, d=.331$, or nonresponding to trivia questions, $t(78)=0.806, p=.423, d=.195, d=.027$, between groups. Finally, there were no significant PM performance differences between males and females on non-focal event-based $\mathrm{PM}, t(78)=.094, p=.925$, or time-based PM, $t(78)=.667, p=.507, d=.177$.

\section{Discussion}

Stress is something that everyone experiences. According to The World Health Organization (WHO), stress is one of the most significant health concerns of the $21^{\text {st }}$ century (World Health Report, 2001). Given the ubiquity and significance of stress in everyday life, it is vital to increase our understanding of how stress impacts the ability to realize intentions in the future. The present study provides novel data towards that effort, and is the first empirical study investigating how stress relates to non-focal event-based PM. Contrary to our hypotheses, the 
results of the current study reveal that acute stress was not significantly related to non-focal event- or time-based PM. These results are similar to those reported by Walser et al. (2013), who also reported a lack of relation between acute stress and PM performance. These findings diverge from the findings of Nater et al. (2006) and Glienke and Piefke (2016), who found that acute stress conditions enhanced time-based PM, or both types of PM, respectively.

In the current study, acute stress was not related to non-focal event-based PM performance. This finding is consistent with existing research investigating the impact of stress on event-based PM more generally (Nakayama et al., 2005; Nater et al., 2006; Walser et al., 2013). Given these consistent findings, it appears that acute stress may not noticeably impact the processes that contribute to event-based PM. Although these results echo previous findings, we had hypothesized that the non-focal nature of the event-based cues would place greater demands on monitoring processes, and thus a relation would emerge in the current study between stress and non-focal event-based PM. Despite a lack of general relations, rising stress levels associated significantly with concurrent improvements in non-focal event-based PM performance $(r=$ 0.840) among a smaller subset (8 participants) who reported the highest levels of stress (e.g., NA scores of over 25). Although this relation emerged only among a small number of participants, it raises the intriguing possibility that increasing levels of acute stress, after a certain point, could enhance non-focal event-based PM performance. If a dose-response relationship does exist with regards to stress and non-focal event-based PM performance, then one might interpret this partially through the Easterbrook hypothesis (1959), where higher levels of arousal might focus one's attentional capacities in favor of identifying target stimuli (Sørensen \& Barratt, 2014; Sørensen, Vangkilde, \& Bundesen, 2014). 
Higher levels of acute stress also did not relate significantly with time-based PM performance, which is counter to the findings of Nater et al. (2006) and Glienke and Piefke (2016). One possibility is that the acute stress experienced in this study did not reach a threshold necessary to influence monitoring behavior (i.e., clock checking) and time-based PM performance. Despite significant differences in self-reported stress levels between groups, our use of a modified TSST protocol, where participants presented to a one-way mirror and video camera, rather than a panel of judges, might not have evoked stress to the levels necessary to modify cognitive functioning (Kelly et al., 2007). For example, Nater et al. (2006) implemented a standard TSST paradigm, in which participants presented to a real audience, and found that acute psychosocial stress enhanced monitoring behavior and time-based PM. Walser and colleagues (2013) also used the standard TSST protocol, but did not quantify time-based PM directly. Therefore, the question remains whether the stress induction paradigm used in this study was sufficient to influence time-based PM performance.

Although acute stress did not seem to influence time-based PM, the perceived stress levels at the outset of the study (i.e., the self-reported stress rating over the previous week) did correlate significantly with enhanced time-based PM and clock-checking behavior, independent of group. This finding indicates that one's time-based PM performance related more to the stress participants brought into the study, rather than the stress induced within the study, and parallels the finding by Ihle et al. (2014). The self-reported global stress measure is believed to tap into chronic stress rather than more short-term, acute stress. Since these self-reported stress levels were retrospective in nature, and potentially influenced by stress levels at the time of the study, firm conclusions about whether this measure assessed chronic stress cannot be made. 
We also analyzed other variables of interest, including participant sex, ongoing task performance, and first- and last-half PM performance, to identify if these might assist in explaining the lack of general relations between acute stress and PM. Participant sex and stress did not contribute to this explanation. Consistent with Walser et al. (2013), there were no differences between male and female performance on event-based PM performance, time-based PM performance, or monitoring behavior. A lack of stress influence also extended to ongoing task performance, indicating that groups did not exhibit differences in monitoring strategy (e.g., attending to PM task at the expense of the ongoing activity). The lack of significant differences between first- and last-half PM performance among those in the experimental group also demonstrates that stress did not differentially influence PM performance over time. However, some research reveals that salivary cortisol levels may peak, or begin to rapidly increase, approximately 15-20-minute after stress induction (Nater et al., 2006; Walser et al., 2013; Shields, Sazma, McCullough, \& Yonelinas, 2017). Therefore, it is possible that the 26-minute task taken shortly after stress induction missed some of the possible points at which stress could influence PM performance.

\section{Conclusions and Future Directions.}

The current state of the literature remains equivocal as to how stress relates with PM. The methodological differences (e.g., laboratory vs. naturalistic, event- vs. time-based PM) between the small number of studies that comprise the literature mean that many important questions remain unanswered. For example, whether stress impacts PM performance appears to depend on many factors, such as the type of stress (e.g., acute or chronic), PM type (e.g., event-based PM versus time-based PM), the validity of the PM task, whether the experiment was laboratorybased or naturalistic, how much cognitive demand and absorption an ongoing task requires 
(Schnitzspahn et al., 2011), and other potential factors, including the time of day stress induction occurs. Further, where stress induction occurs in the PM sequence (i.e., before, during, or after intention encoding, retrieval) also appears to be an important consideration (Shields et al., 2017).

A recent meta-analysis of stress and memory by Shields et al. (2017) revealed several important variables that may moderate the relations between acute stress and memory processes that might assist in explaining the lack of significant relations between acute stress induction and PM performance in this study. One significant moderator of stress effects was the time of day. Specifically, studies that took place in the afternoon exhibited the largest stress effects. Another noteworthy finding was that the delay between stress and encoding created differential impacts on memory, such that in general, as the delay between stress and encoding increased, the effects of stress became more negative. Additionally, post-encoding stress induction led to general episodic memory increases, but this relation emerged only when participants stayed in the same context in which they learned the material, while memory impairments emerged when stress induction took place just before or during retrieval.

Since PM also contains a retrospective component, inducing a state of arousal that is close in time to encoding could modulate memory consolidation, and facilitate intention retrieval later (Cahill et al., 2003; Glienke \& Piefke, 2016; Henckens, Hermans, Pu, Joëls, \& Fernández, 2009; Kuhlmann \& Wolf, 2006; Roozendaal, 2002; Shields et al., 2017). For example, Glienke and Piefke (2016) found that when inducing acute stress before the intention formation stage, participants maintained stable (and higher) event- and time-based PM performance, relative to those who did not undergo stress induction procedures, especially towards the end of the week. Further, their study indicates that the impact of acute stress may persist over time, given the stability in both event-based and time-based PM performance over longer periods of time among 
those who were stressed compared to non-stressed counterparts. Many of the studies in the area, including the present study, investigate only how acute stress relates with PM performance in the short-term. Another factor that might moderate the relations between stress and PM is whether these variables follow a dose-response curve. Research demonstrates that stress may influence memory performance according to an inverted ' $U$ ' dose-response curve, similar to the YerkesDodson law (1908), where GCs enhance memory on the top of this inverted U, and impair memory with excess or deficient GC levels. It remains unknown whether stress interacts with PM in this fashion. This type of pattern might assist in accounting for the varied results found in the existing literature. Future research can assist in specifying which conditions might influence time-based PM, as well as parse out the impact of acute stress, chronic stress, and their potential interaction, on PM.

\section{Limitations.}

There are several limitations of the study that warrant acknowledgement. First, despite the sample characteristics approximating the overall Montana population according to the Montana State Census (2010), the participant sample collected for the study was relatively homogenous, consisting mainly of young Caucasian college students at the University of Montana. This may limit the generalizability of the results outside of the state of this context. Another limitation regards the PM paradigm used for the study. The use of difficult trivia as an ongoing task with embedded non-focal event-based target cues and time-based target times likely made the task itself difficult for participants. Although overall task difficulty might have been greater than intended, task difficulty did not differ between groups, calling into question whether the overall difficulty of this task had any bearing on the lack of associations between stress and PM. Given that the event-based cues were non-focal, one might expect lowered performance on 
such a task due to the increased monitoring resources required to identify the cues. However, the hope was that the use of a challenging ongoing task, as well as non-focal event-based and timebased components, would place greater demands on the self-initiated processing that stress influences, thereby providing an opportunity to observe the relations between stress and PM. Another limitation surrounds the fact that the PM task began immediately following stress induction (i.e., rather than after a short delay) may have also prevented collecting data during points at which stress continued to influence participants. Lastly, participant screening did not assess for the use of contraceptives or other hormone-modifying substances, which have been shown to modify the interaction between stress and memory (Shield et al., 2017).

\section{Summary.}

In summary, the results of the current study suggest that the ability to carry out eventand time-based intentions may remain preserved even under acute stress conditions. This is the

first study to test how stress relates with event-based PM when using non-focal cues. Although there was no general effect of stress on this type of PM, the strong correlation between increasing levels of stress and non-focal event-based PM performance among those with the highest levels of reported stress may provide an initial indication of a dose-response relation. Additionally, higher levels of perceived stress before stress induction (chronic stress) also correlated with monitoring behavior and time-based PM performance, signifying that stress may convey benefits to one's ability to monitor, and in turn execute, intentions related to time. Although this area requires additional research before drawing more definitive conclusions, it appears that stress may differentially influence PM abilities depending on several factors. Delineating these relations will enable a more holistic understanding of how the common experience of stress impacts the ability to complete intentions in the future. 


\section{References}

Altgassen, M., Kliegel, M., \& Martin, M. (2009). Event-based prospective memory in depression: The impact of cue focality. Cognition and Emotion, 23(6), 1041-1055.

Arnsten, A. F. (2000). Stress impairs prefrontal cortical function in rats and monkeys: Role of dopamine D1 and norepinephrine alpha-1 receptor mechanisms. Progress in Brain Research, 126, 183-192.

Arnsten, A. F. T. (2009). Stress signaling pathways that impair prefrontal cortex structure and function. Nature Reviews Neuroscience, 10(6), 410-422.

Asmundson, G. J. G., \& Taylor, S. (2005). It's not all in your head: How worrying about your health could be making you sick - and what you can do about it. New York, NY: The Guilford Press.

Baum, A. (1990). Stress, intrusive imagery, and chronic distress. Health Psychology, 9(6), 653675.

Braunstein-Bercovitz, H. (2003). Does stress enhance or impair selective attention? The effects of stress and perceptual load on negative priming. Anxiety, Stress, and Coping, 16, 345357.

Belanoff, J. K., Gross, K., Yager, A., \& Schatzberg, A. F. (2001). Corticosteroids and cognition. Journal of Psychiatric Research, 35, 127-145.

Benoit, R. G., Gilbert, S. J., Frith, C. D., \& Burgess, P. W. (2012). Rostral prefrontal cortex and the focus of attention in prospective memory. Cerebral Cortex, 22(8), 1876-1886.

Birkett, M. A. (2011). The trier social stress test protocol for inducing psychological stress. Journal of Visualized Experiments, 56, 3238. 
Bisiacchi, P. S., Schiff, S., Ciccola, A., \& Kliegel, M. (2009). The role of dual-task and taskswitch in prospective memory: Behavioural data and neural correlates. Neuropsychologia, 47(5), 1362-1373.

Brand, N., Schneider, N., \& Arntz, P. (1995). Information processing efficiency and noise: Interactions with personal rigidity. Personality and Individual Differences, 18, 571-579.

Brandimonte, M. A., Einstein, G. O., \& McDaniel, M. A. (1996). Prospective Memory: Theory and Applications. Mahwah, NJ: Erlbaum.

Brunner, R., Schaefer, D., Hess, K., Parzer, P., Resch, F., \& Schwab, S. (2005). Effect of corticosteroids on short-term and long-term memory. Neurology, 64, 335-337.

Bugg, J. M., McDaniel, M. A., \& Einstein, G. O. (2013). Event-based prospective remembering: An integration of prospective memory and cognitive control theories. In D. Reisberg (Ed.), The Oxford handbook of cognitive psychology (pp. 267-282). New York, NY: Oxford University Press.

Burgess P. W., Quayle, A., \& Frith, C. D. (2001). Brain regions involved in prospective memory as determined by positron emission tomography. Neuropsychologia, 39, 545-555.

Burgess, P. W., Scott, S. K., \& Frith, C. D. (2003). The role of the rostral frontal cortex (area 10) in prospective memory: A lateral versus medial dissociation. Neuropsychologia, 41, 906918.

Burgess P. W., Veitch, E., Costello, A., \& Shallice, T. (2000). The cognitive and neuroanatomical correlates of multitasking. Neuropsychologia, 38, 848-863.

Carver, L., \& Cluver, A. (2009). Stress effects on the brain system underlying explicit memory. In J. A. Quas, \& R. Fivush (Eds.), Emotion and memory in development: 
Biological, cognitive, and social considerations (pp. 278-312). New York, NY, US: Oxford University Press.

Cahill, L., Lukasz, G., \& Kathryn, L. (2003). Enhanced human memory consolidation with postlearning Stress: Interaction with the degree of arousal at encoding. Learning \& Memory, $10(4), 270-274$.

Chajut, E., \& Algom, D. (2003). Selective attention improves under stress: Implications for theories of social cognition. Journal of Personality and Social Psychology, 85, 231-248.

Cohen, A.-L., Jaudus, A., \& Gollwitzer, P. M. (2008). Number of cues influences the cost of remembering to remember. Memory \& Cognition, 36(1), 149-156.

Cohen, S., Kamarck, T., \& Mermelstein, R. (1983). A global measure of perceived stress. Journal of Health and Social Behavior, 24, 385-396.

Cohen, S., Kessler, R. C., \& Gordon, L. U. (1997). Measuring Stress: A Guide for Health and Social Scientists. New York: Oxford University Press.

Costa, A., Caltagirone, C., \& Carlesimo, G. A. (2011). Prospective memory impairment in mild cognitive impairment: An analytical review. Neuropsychology Review, 21(4), 390404.

Costa, A., Carlesimo, G. A., \& Caltagirone, C. (2012). Prospective memory functioning: A new area of investigation in the clinical neuropsychology and rehabilitation of Parkinson's disease and mild cognitive impairment. Review of evidence. Neurological Sciences, $33(5), 965-972$.

Craik, F. I. M. (1986). A functional account of age differences in memory. In F. Klix \& H. Hagendorf (Eds.), Human memory and cognitive capabilities: Mechanisms and performances (pp. 409-422). North-Holland; Elsevier Science Publishers, B.V. 
Crawford, J. R., \& Henry, J. D. (2004). The Positive and Negative Affect Schedule (PANAS): Construct validity, measurement properties and normative data in a large non-clinical sample. British Journal of Clinical Psychology, 43, 245-265.

Crovitz, H. F., \& Daniel, W. F. (1984). Measurements of everyday memory: Toward the prevention of forgetting. Bulletin of the Psychonomic Society, 22(5), 413-414.

Dedovic, K., D’Aguiar, C., \& Pruessner, J. C. (2009). What stress does to your brain: A review of neuroimaging studies. The Canadian Journal of Psychiatry, 54(1), 6-15.

de Kloet, E. R., Oitzl, M. S., \& Joels, M. (1999). Stress and cognition: Are corticosteroids good or bad guys? Trends Neuroscience, 22(10), 422-426.

de Quervain, D. J., Aerni, A., Schelling, G., \& Roozendaal, B. (2009). Glucocorticoids and the regulation of memory in health and disease. Frontiers in Neuroendocrinology, 30, 358370.

de Quervain, D. J., Henke, K., Aerni, A., Treyer, V., McGaugh, J. L., Berthold, T., et al. (2003). Glucocorticoid-induced impairment of declarative memory retrieval is associated with reduced blood flow in the medial temporal lobe. European Journal of Neuroscience, 17(6), 1296-1302.

de Quervain, D. J., Roozendaal, B., Nitsch, R. M., McGaugh, J. L., \& Hock, C. (2000). Acute cortisone administration impairs retrieval of long-term declarative memory in humans. Nature Neuroscience, 3(4), 313-314.

Dua, J. K. (1993). The role of negative affect and positive affect in stress, depression, selfesteem, assertiveness, Type A behaviors, psychological health, and physical health. Genetic, Social, and General Psychology Monographs, 119, 515-552. 
d'Ydewalle, G., Bouchaert, D., \& Brunfaut, E. (2001). Age-related differences and complexity of ongoing activities in time- and event-based prospective memory. The American Journal of Psychology, 114(3), 411-423.

Easterbrook, J. A. (1959). The effect of emotion on cue utilization and the organization of behavior. Psychological Review, 66, 183-201.

Echterhoff, G., \& Wolf, O. T. (2012). The stressed eyewitness: The interaction of thematic arousal and post-event stress in memory for central and peripheral event information. Frontiers in Integrative Neuroscience, 6, 51-62.

Einstein, G. O., Holland, L. J., McDaniel, M. A, \& Guynn, M. J. (1992). Age-related deficits in prospective memory: The influence of task complexity. Psychology and Aging, 7, 471478.

Einstein, G. O., \& McDaniel, M. A. (1990). Normal aging and prospective memory. Journal of Experimental Psychology: Learning, Memory, \& Cognition, 16(4), 717-726.

Einstein, G. O., \& McDaniel, M. A. (2010). Prospective memory and what costs do not reveal about retrieval processes: A commentary on Smith, Hunt, McVay, and McConnell (2007). Journal of Experimental Psychology: Learning, Memory, and Cognition, 36, 1082-1088.

Einstein, G. O., \& McDaniel, M. A. (1996). Retrieval processes in prospective memory: Theoretical approaches and some new findings. In M. Brandimonte, G. O. Einstein, \& M. A. McDaniel (Eds.), Prospective memory: Theory and applications (pp. 115-142). Mahwah, NJ: Lawrence Erlbaum Associates Inc.

Einstein, G. O., McDaniel, M. A., Shank, H., \& Mayfield, S. (2002). The costs of performing a prospective memory task on cover activities: Support for the 
multiprocess view. Poster presented at the meeting of the Psychonomic Society, Kansas City, MO.

Einstein, G. O., McDaniel, M. A., Ruthann, T., Mayfield, S., Shank, H., Morrisette, N., \& Breneiser, J. (2005). Multiple processes in prospective memory retrieval: Factors determining monitoring versus spontaneous retrieval. Journal of Experimental Psychology: General, 134(3), 327-342.

Einstein, G. O., Smith, R. E., McDaniel, M. A., \& Shaw, P. (1997). Aging and prospective memory: The influence of increased task demands at encoding and retrieval. Psychology and Aging, 12(3), 479-488.

Ellis, J. A. (1996). Prospective memory or the realization of delayed intentions: A conceptual framework for research. In M. Brandimonte, G. O. Einstein, \& M. A. McDaniel (Eds.), Prospective memory: Theory and applications (pp. 1-22). Mahwah, NJ: Lawrence Erlbaum Associates Inc.

Ferris, C. F., \& Stolberg, T. (2010). Imaging the immediate non-genomic effects of stress hormone on brain activity. Psychoneuroendocrinology, 35, 5-14.

Goldstein, L. H., Bernard, S., Fenwick, P. B. C., Burgess, P. W., \& McNeil, J. (1993). Unilateral frontal lobectomy can produce strategy application disorder. Journal of Neurology, Neurosurgery and Psychiatry, 56, 274-276.

Gordon, B. A., Shelton, J. T., Bugg, J. M., McDaniel, M. A., \& Head, D. (2011). Structural correlates of prospective memory. Neuropsychologia, 49(14), 3795-3800.

Guynn, M. J. (2003). A two-process model of strategic monitoring in event-based prospective memory: Activation/retrieval mode and target checking. International Journal of Psychology, 38, 245-256. 
Harris, J. E., \& Wilkins, A. J. (1982). Remembering to do things: A theoretical framework and an illustrative experiment. Human Learning, 1, 123-136.

Henckens, M. J. a. G., Hermans, E. J., Pu, Z., Joëls, M., \& Fernández, G. (2009). Stressed memories: How acute stress affects memory formation in humans. The Journal of Neuroscience, 29(32), 10111-10119.

Het, S., Ramlow, G., \& Wolf, O. T. (2005). A meta-analytic review of the effects of acute cortisol administration on human memory. Psychoneuroendocrinology, 30, 771-784.

Hoes, M. J. (1986). Stress and strain: Their definition, psychobiology and relationship to psychosomatic medicine. Journal of Orthomolecular Medicine, 1(1), 30-38.

Ihle, A., Kliegel, M., Hering, A., Ballhausen, N., Lagner, P., Benusch, J., et al. (2014). Adult age differences in prospective memory in the laboratory: Are they related to higher stress levels in the elderly? Frontiers in Human Neuroscience, 8, 11-21.

Ihle, A., Schnitzspahn, K. M., Rendell, P. G., Luong, C., \& Kliegel, M. (2012). Age benefits in everyday prospective memory: The influence of personal task importance, use of reminders and everyday stress. Aging, Neuropsychology, and Cognition, 19(1-2), 84-101.

Keinan, G., Friedland, N., Kahneman, D., \& Roth, D. (1999). The effect of stress on the suppression of erroneous competing responses. Anxiety, Stress, and Coping, 12, 455-476.

Kelly, O., Matheson, K., Martinez, A., Merali, Z., \& Anisman, H. (2007). Psychosocial stress evoked by a virtual audience: Relation to neuroendocrine activity. CyberPsychology \& Behavior, 10(5), 655-662.

Kerns, K. A., \& Price, K. J. (2001). An investigation of prospective memory in children with ADHD. Child Neuropsychology, 7(3), 162-171. 
Kirschbaum, C., Kudielka, B. M., Gaab, J., Schommer, N. C., \& Hellhammer, D. H. (1999). Impact of gender, menstrual cycle phase, and oral contraceptives on the activity of the hypothalamus-pituitary-adrenal axis. Psychosomatic Medicine, 61(2), 154-162.

Kirschbaum, C., Pirke, K. M., \& Hellhammer, D. H. (1993). The "Trier Social Stress Test": A tool for investigating psychobiological stress responses in a laboratory setting. Neuropsychobiology, 28, 76-81.

Kirschbaum, C., Wolf, O. T., May, M., Wippich, W., \& Hellhammer, D. H., (1996). Stress- and treatment-induced elevations of cortisol levels associated with impaired declarative memory in healthy adults. Life Sciences, 58, 1475-1483.

Klein, S. B. (2013). The temporal orientation of memory: It's time for a change of direction. Journal of Applied Research in Memory and Cognition, 2, 222-234.

Kliegel, M., Altgassen, M., Hering, A., \& Rose, N. (2011). A processmodel based approach to prospective memory impairment in Parkinson's disease. Neuropsychologia, 49, 21662177.

Kliegel, M., Jäger, T., \& Phillips, L. H. (2008). Adult age differences in event-based prospective memory: A meta-analysis on the role of focal versus nonfocal cues. Psychology and Aging, 23(1), 203-208.

Kliegel, M., Jäger, T., Phillips, L. H., Federspiel, E., Imfeld, A. et al. (2005). Effects of sad mood on time-based prospective memory. Cognition and Emotion, 19(8), 1199-1213.

Kliegel, M., Martin, M., McDaniel, M. A., \& Einstein, G. O. (2002). Complex prospective memory and executive control of working memory: A process model. Psychologische Beiträge, 44, 303-318. 
Kliegel, M., Martin, M., McDaniel, M. A., \& Einstein, G. O. (2001). Varying the importance of a prospective memory task: Differential effects across time- and event-based prospective memory. Memory, 9(1), 1-11.

Kliegel, M., Ropeter, A., \& Mackinlay, R. (2006). Complex prospective memory in children with ADHD. Child Neuropsychology, 12, 407-419.

Kofman, O., Meiran, N., Greenberg, E., Balas, M., \& Cohen, H. (2006). Enhanced performance on executive functions associated with examination stress: Evidence from task-switching and Stroop paradigms. Cognition and Emotion, 20(5), 577-595.

Kudielka, B. M., Hellhammer, D. H., \& Kirschbaum, C. (2007). Ten years of research with the trier social stress rest-revisited. In J. E. Harmon, \& P. Winkielman (Eds.), Social neuroscience: Integrating biological and psychological explanations of social behavior (56-83). New York, NY, US: Guilford Press.

Kudielka, B. M., Schommer, N. C., Hellhammer, D. H., \& Kirschbaum, C. (2004). Acute HPA axis responses, heart rate, and mood changes to psychosocial stress (TSST) in humans at different times of day. Psychoneuroendocrinology, 29(8), 983-992.

Kuhlmann, S., \& Wolf, O. T. (2006). Arousal and cortisol interact in modulating memory consolidation in healthy young men. Behavioral Neuroscience, 120(1), 217-223.

LeDoux, J. E. (1998). The Emotional Brain: The Mysterious Underpinnings of Emotional Life. London: Weidenfeld and Nicolson.

Liston, C., Miller, M. M., Goldwater, D. S., Radley, J. J., Rocher, A. B., Hof, P. R., et al. (2006). Stress-induced alterations in prefrontal cortical dendritic morphology predict selective impairments in perceptual attentional set-shifting. Journal of Neuroscience, 26(30), 7870-7874. 
Luethi, M., Meier, B., \& Sandi, C. (2009). Stress effects on working memory, explicit memory, and implicit memory for neutral and emotional stimuli in healthy men. Frontiers in Behavioral Neuroscience, 2, 1-9.

Lupien, S. J. (2009). Brains under stress. The Canadian Journal of Psychiatry, 54(1), 4-5.

Lupien, S. J., Fiocco, A., Wan, N., Maheu, F., Lord, C., Schramek, T., \& Tu, M. T. (2005). Stress hormones and human memory function across the lifespan. Psychoneuroendocrinology, 30, 225-242.

Lupien, S. J., Gillin, C., \& Hauger, R. L. (1999). Working memory is more sensitive than declarative memory to the acute effects of corticosteroids: A dose-response study. Behavioral Neuroscience, 113, 420-430.

Lupien, S. J., \& Lepage, M. (2001). Stress, memory, and the hippocampus: Can't live with it, can't live without it. Behavioural Brain Research, 127, 137-158.

Lupien, S. J., Maheu, F., Tu, M., Fiocco, A., \& Schramek, T. E. (2007). The effects of stress and stress hormones on human cognition: Implications for the field of brain and cognition. Brain and Cognition, 65(3), 209-237.

Lupien, S. J., \& McEwen, B. S. (1997). The acute effects of corticosteroids on cognition: Integration of animal and human model studies. Brain Research, 24, 1-27.

Lupien, S. J., Ouelle-Morin, I., Hupback, A., Walker, D., Tu, M. T., \& Buss, C. (2006). In D. Cicchetti (Ed.), Beyond the stress concept: Allostatic load-a developmental biological and cognitive perspective. Handbook series on developmental psychopathology (pp. 784809). Wisconsin. 
Lupien, S. J., Wilkinson, C. W., Briere, S., Menard, C., Ng Ying Kin, N. M., \& Nair, N. P. (2002). The modulatory effects of corticosteroids on cognition: Studies in young human populations. Psychoneuroendocrinology, 27(3), 401-416.

Marin, M.-F., Pilgrim, K., \& Lupien, S. J. (2010). Modulatory effects of stress on reactivated emotional memories. Psychoneuroendocrinology, 35(9), 1388-1396.

Marsh, R. L., Hicks, J. L., Cook, G. I., Hansen, J. S., \& Pallos, A. L. (2003). Interference to ongoing activities covaries with the characteristics of an event-based intention. Journal of Experimental Psychology: Learning, Memory and Cognition, 29, 861-870.

Marsh, R. L., Hicks, J. L. \& Watson, V. (2002). The dynamics of intention retrieval and coordination of action in event-based prospective memory. Journal of Experimental Psychology: Learning, Memory, and Cognition, 28, 652-659.

Martin, M., Kliegel, M., \& McDaniel, M. (2003). The involvement of executive functions in prospective memory performance of adults. International Journal of Psychology, 38, 195-206.

Martin, T., McDaniel, M. A., Guynn, M. J., Houck, J. M., Woodruff, C. C., et al. (2007). Brain regions and their dynamics in prospective memory retrieval: A MEG study. International Journal of Psychophysiology, 64(3), 247-258.

Maylor, E. A. (1996). Age-related impairment in an event-based prospective memory task. Psychology and Aging, 11, 74-78.

McDaniel, M. A., \& Einstein, G. O. (2007). Prospective memory: An overview and synthesis of an emerging field. Thousand Oaks, CA, US: Sage Publications, Inc. 
McDaniel, M. A., \& Einstein, G. O. (2000). Strategic and automatic processes in prospective memory retrieval: A multiprocess framework. Applied Cognitive Psychology, 14, S127S144.

McDaniel, M. A., Einstein, G. O., \& Rendell, P. G. (2008). The puzzle of inconsistent agerelated declines in prospective memory: A multiprocess explanation. In M. Kliegel, M. A. McDaniel, \& G. O. Einstein (Eds.), Prospective memory: Cognitive, neuroscience, developmental, and applied perspectives (pp. 141-160). Mahwah NJ: Lawrence Erlbaum.

McDaniel, M. A., Glisky, E. L., Guynn, M. J., \& Routhieaux, B. C. (1999). Prospective memory: A neuropsychological study. Neuropsychology, 13(1), 103-110.

McDaniel, M. A., Guynn, M. J., Einstein, G. O., \& Breneiser, J. (2004). Cue-focused and reflexive-associative processes in prospective memory retrieval. Journal of Experimental Psychology: Learning, Memory, \& Cognition, 30, 605-614.

McDaniel, M. A., Shelton, J. T., Breneiser, J. E., Moynan, S., \& Balota, D. A. (2011). Focal and nonfocal prospective memory performance in very mild dementia: A signature decline. Neuropsychology, 25, 387-396.

McFarland, C. P., \& Glisky, E. L. (2011). Implementation intentions and prospective memory among older adults: An investigation of the role of frontal lobe function. Aging, Neuropsychology, and Cognition: A Journal on Normal and Dysfunctional Development, $18(6), 663-652$.

McFarland, C. P., \& Glisky, E. L. (2009). Frontal lobe involvement in a task of time-based prospective memory. Neuropsychologia, 47, 1660-1669.

Meeks, J. T., Rosnick, C. B., Blackhurst, J., \& Overton, A. (2014). Does Sex Matter? The moderating role of sex on the relationship between stress biomarkers and cognition. 
Current Psychology: A Journal for Diverse Perspectives on Diverse Psychological Issues, 33(2), 199-218.

Merz, E. L., \& Roesch, S. C. (2011). Modeling trait and state variation using multilevel factor analysis with PANAS daily diary data. Journal of Research in Personality 45, 2-9.

Mika, A., Mazur, G. J., Hoffman, A. N., Talboom, J. S., Bimonte-Nelson, H. A., Sanabria, F., \& Conrad, C. D. (2012). Chronic stress impairs prefrontal cortex-dependent response inhibition and spatial working memory. Behavioral Neuroscience, 126(5), 605-619.

Miller, E. K., \& Cohen, J. D. (2001). An integrative theory of prefrontal cortex function. Annual Review of Neuroscience, 24, 167-202.

Miyake, A., Friedman, N. P., Emerson, M. J., Witzki, A. H., Howerter, A., \& Wagner, T. D. (2000). The unity and diversity of executive functions and their contributions to complex "frontal lobe" tasks: A latent variable analysis. Cognitive Psychology, 41, 49-100.

Montana State Census. (2010). Profiles of general population \& housing characteristics. Retrieved from http://ceic.mt.gov/Population/PopulationAndHousingProfiles.aspx.

Morishima, Y., Okuda, J., \& Sakai, K. (2010). Reactive mechanism of cognitive control system. Cerebral Cortex, 20(11), 2675-2683.

Nakayama, Y., Takahashi, T., \& Radford, M. H. (2005). Cortisol levels and prospective and retrospective memory in humans. Neuroendocrinology Letters, 26(5), 599-602.

Nater, U. M., Okere, U., Stallkamp, R., Moor, C., Ehlert, U., \& Kliegel, M. (2006). Psychosocial stress enhances time-based prospective memory in healthy young men. Neurobiology of Learning and Memory, 86, 344-348. 
Oei, N. Y., Everaerd, W. T., Elzinga, B. M., van Well, S., \& Bermond, B. (2006). Psychosocial stress impairs working memory at high loads: An association with cortisol levels and memory retrieval. Stress, 9, 133-141.

Okuda, J., Fujii, T., Ohtake, H., Tsukiura, T., Yamadori, A., Frith, C. D., et al. (2007). Differential involvement of regions of rostral prefrontal cortex (Brodmann area 10) in time- and event-based prospective memory. International Journal of Psychophysiology, 64, 233-246.

Okuda, J., Fujii, T., Yamadori, A., Kawashima, R., Tsukiura, T., Fukatsu, R., et al. (1998). Participation of the prefrontal cortices in prospective memory: Evidence from a PET study in humans. Neuroscience Letters, 253, 127-130.

Okuda, J., Gilbert, S. J., Burgess, P. W., Frith, C. D., \& Simons, J. S. (2011). Looking to the future: Automatic regulation of attention between current performance and future plans. Neuropsychologia, 49, 2258-2271.

Paller, K. A., \& Kutas, M. (1992). Brain potentials during retrieval provide neurophysiological support for the distinction between conscious recollection and priming. Journal of Cognitive Neuroscience, 4, 375-391.

Payne, J. D., Jackson, E. D., Hoscheidt, S., Ryan, L., Jacobs, W. J., \& Nadel, L. (2007). Stress administered prior to encoding impairs neutral but enhances emotional long-term episodic memories. Learning and Memory, 14, 861-868.

Payne, J. D., Jackson, E. D., Ryan, L., Hoscheidt, S., Jacobs, J. W., \& Nadel, L. (2006). The impact of stress on neutral and emotional aspects of episodic memory. Memory, 14, 1-16.

Payne, J. D., Nadel, N., Allen, J. J. B., Thomas, K. G. F., \& Jacobs, J. (2002). The effects of experimentally induced stress on false recognition. Memory, 10(1), 1-6. 
Polk, D. E., Cohen, S., Doyle, W. J., Skoner, D. P., \& Kirschbaum, C. (2005). State and trait affect as predictors of salivary control in healthy adults. Psychoneuroendocrinology, 30, 261-272.

Raskin, S. (2004). Memory For Intentions Screening Test (abstract). Journal of the International Neuropsychological Society, 10(Suppl. 1) 110.

Reising, M. M. (2014). The effects of chronic stress on executive function, coping, and prefrontal function in children of depressed parents. Dissertation Abstracts International: Section B: The Sciences and Engineering, 75(2-B).

Roozendaal, B. (2000). Glucocorticoids and the regulation of memory consolidation. Psychoneuroendocrinology, 25, 213-238.

Roozendaal, B. (2002). Stress and memory: Opposing effects of glucocorticoids on memory consolidation and memory retrieval. Neurobiology of Learning and Memory, 78, 578595.

Roozendaal, B., \& de Quervain, D. J. (2005). Glucocorticoid therapy and memory function: Lessons learned from basic research. Neurology, 64(2), 184-185.

Roozendaal, B., Griffith, Q. K., Buranday, J., de Quervain, D. J., \& McGaugh, J. L. (2003). The hippocampus mediates glucocorticoid-induced impairment of spatial memory retrieval: Dependence on the basolateral amygdala. Proceedings of the National Academy of Sciences of the United States of America, 100(3), 1328-1333.

Rose, N. S., Rendell, P., McDaniel, M., Aberle, I., \& Kliegel, M. (2010). Age and individual differences in prospective memory during a "Virtual Week": The role of working memory, vigilance, task-regularity, and cue-focality. Psychology and Aging, 25(3), 595605. 
Rude, S. S., Hertel, P. T., Jarrold, W., Covich, J., \& Hedlund, S. (1999). Depression-related impairments in prospective memory. Cognition and Emotion, 13, 267-276.

Salthouse, T. A., Berish, D. E., \& Siedlecki, K. L. (2004). Construct validity and age sensitivity of prospective memory. Memory \& Cognition, 32, 1133-1148.

Sapolsky, R. M. (2000). Glucocorticoids and hippocampal atrophy in neuropsychiatric disorders. Archives of General Psychiatry, 57, 925-935.

Schnitzspahn, K. M., Ihle, A., Henry, J. D., Rendell, P. G., \& Kliegel, M. (2011). The ageprospective memory-paradox: An exploration of possible mechanisms. International Psychogeriatrics, 23(4), 583-592.

Schnitzspahn, K. M., Stahl, C., Zeintl, M., Kaller, C. P., \& Kliegel, M. (2013). The role of shifting, updating, and inhibition in prospective memory performance in young and older adults. Developmental Psychology, 49(8), 1544-1553.

Schwabe, L., Haddad, L., \& Schachinger, H. (2008). HPA axis activation by a socially evaluated cold-pressor test. Psychoneuroendocrinology, 33, 890-895.

Scullin, M. K., McDaniel, M. A., \& Einstein, G. O. (2010). Control of cost in prospective memory: Evidence for spontaneous retrieval processes. Journal of Experimental Psychology: Learning, Memory, and Cognition, 36(1), 190-203.

Selye, H. (1998). A syndrome produced by diverse nocuous agents. 1936. The Journal of Neuropsychiatry and Clinical Neurosciences, 10(2), 230-231.

Selye, H. (1975). Confusion and controversy in the stress field. Journal of Human Stress, 1(2), $37-44$.

Shallice, T., \& Burgess, P. W. (1991). Deficits in strategy application following frontal lobe damage in man. Brain, 114, 727-741. 
Shields, G. S., Sazma, M. A., McCullough, A. M., \& Yonelinas, A. P. (2017). The effects of acute stress on episodic memory: A meta-analysis and integrative review. Psychological Bulletin, Advance online publication. http://dx.doi.org/10.1037/bul0000100.

Shields, G. S., Sazma, M. A., \& Yonelinas, A. P. (2016). The effects of acute stress on core executive functions: A meta-analysis and comparison with cortisol. Neuroscience and Biobehavioral Reviews, 68, 651-668.

Simons, J. S., Schölvinck, M., Gilbert, S. J., Frith, C. D., \& Burgess, P. W. (2006). Differential components of prospective memory? Evidence from fMRI. Neuropsychologia, 44, 13881397.

Skosnik, P. D., Chatterton Jr., R. T., Swisher, T., \& Park, S. (2000). Modulation of 133 attentional inhibition by norepinephrine and cortisol after psychological stress. International Journal of Psychophysiology, 36, 59-68.

Smeets, T., Jelicic, M., \& Merckelbach, H. (2006). The effect of acute stress on memory depends on word valence. International Journal of Psychophysiology, 62(1), 30-37.

Smeets, T., Otgaar, H., Candel, I., \& Wolf, O. T. (2008). True or false? Memory is differentially affected by stress-induced cortisol elevations and sympathetic activity at consolidation and retrieval. Psychoneuroendocrinology, 33(10), 1378-1386.

Smith, R. E. (2003). The cost of remembering to remember in event-based prospective memory: Investigating the capacity demands of delayed intention performance. Journal of Experimental Psychology: Learning, Memory and Cognition, 29, 347-361.

Smith, R. E. (2010). What costs do reveal and moving beyond the cost debate: Reply to Einstein and McDaniel (2010). Journal of Experimental Psychology: Learning, Memory, and Cognition, 36, 1089-1095. 
Smith, R. E., \& Bayen, U. J. (2004). A multinomial model of event-based prospective memory. Journal of Experimental Psychology: Learning, Memory, and Cognition, 30(4), 756-777.

Smith, R. E., \& Bayen, U. J. (2005). The effects of working memory resource availability on prospective memory: A formal modeling approach. Experimental Psychology, 52(4), 243-256.

Smith, R. E., Hunt, R. R., McVay, J. C., \& McConnell, M. D. (2007). The cost of event-based prospective memory: Salient target events. Journal of Experimental Psychology: Learning, Memory, \& Cognition, 33(4), 734-746.

Sørensen, T. A., \& Barratt, D. (2014). Is threat the only modulator of attentional selectivity? redefining the Easterbrook hypothesis. Frontiers in Psychology, 5(1), article 1020.

Sørensen, T. A., Vangkilde, S., and Bundesen, C. (2014). Two mechanisms of arousal in attention: How arousal affects encoding into visual short-term memory. Journal of Experimental Psychology: Learning, Memory, and Cognition, 41(1), 178-192.

Stawsky, R. S. (2007). Examination of the effects of exposure to stress and stress-reactivity on selective attention performance. Dissertation Abstracts International: Section B: The Sciences and Engineering, 67(11-B), 6760.

Steinhauser, M., Maier, M., \& Hübner, R. (2007). Cognitive control under stress: How stress affects strategies of task-set reconfiguration. Psychological Science, 18(6), 540-545.

Tam, J. W., \& Schmitter-Edgecombe, M. (2013). Event-based prospective memory and everyday forgetting in healthy older adults and individuals with mild cognitive impairment. Experimental Neuropsychology, 35(3), 279-290.

Terry, W. S. (1988). Everyday forgetting: Data from a diary study. Psychological Reports, 62, 299-303. 
Timko, C., Moos, R. H., \& Michelson, D. J. (1993). The contexts of adolescents' chronic life stressors. American Journal of Community Psychology, 21(4), 397-420.

Tulving, E. (1983). Elements of Episodic Memory. Oxford: Oxford University Press.

Unsworth, N., McMillan, B. D., Brewer, G. A., \& Spillers, G. J. (2013). Individual differences in everyday retrospective memory failures. Journal of Applied Research in Memory and Cognition, 2, 7-13.

Qin, S., Hermans, E. J., van Marle, H. J. F., Luo, J., \& Fernandez, G. (2009). Acute psychological stress reduces working memory-related activity in the dorsolateral prefrontal cortex. Biological Psychiatry, 66(1), 25-32.

Van Cauter, E., \& Turek, F. W. (1994). Endocrine and other biological rhythms. In L. J. DeGroot (Ed.), Endocrinology (pp. 2487-2548). Philadelphia: W. B. Saunders.

von Dawans, B., Kirschbaum, C., \& Heinrichs, M. (2011). The Trier Social Stress Test for Groups (TSST-G): A new research tool for controlled simultaneous social stress exposure in a group format. Psychoneuroendocrinology, 36(4), 514-522.

Walser, M., Fischer, R., Goschke, T., Kirschbaum, C., \& Plessow, F. (2013). Intention retrieval and deactivation following an acute psychosocial stressor. PLOS ONE, 8(12), e85685.

Wang, J., Korczykowski, M., Rao, H., Fan, Y., Pluta, J., Gur, R. C., McEwen, B. S., \& Detre, J. A. (2007). Gender difference in neural response to psychological stress. Social Cognitive and Affective Neuroscience, 2(3), 227-239.

Watson, D., Clark, L. A., \& Tellegen, A. (1988). Development and validation of brief measures of positive and negative affect: The PANAS scales. Journal of Personality and Social Psychology, 47, 1063-1070. 
Watson, D. (1988). The vicissitudes of mood measurement: Effects of varying descriptors, time frames, and response formats on measures of positive and negative affect. Journal of Personality and Social Psychology, 55, 128-141.

West, R., Bowry, R., \& Krompinger, J. (2006). The effects of working memory demands on the neural correlates of prospective memory. Neuropsychologia, 44, 197-297.

West, R., Herndon, R. W., \& Crewdson, S. J. (2001). Neural activity associated with the realization of a delayed intention. Cognitive Brain Research, 12, 1-10.

West, R., Herndon, R. W., \& Ross-Munroe, K. (2000). Event-related neural activity associated with prospective remembering. Applied Cognitive Psychology, 14, S115-S126.

West, R., \& Krompinger, J. (2005). Neural correlates of prospective and retrospective memory. Neuropsychologia, 43(3), 418-433.

West, R., \& Ross-Munroe, K. (2002). Neural correlates of the formation and realization of delayed intentions. Cognitive, Affective, and Behavioral Neuroscience, 2, 162-173.

West, R. (2007). The influence of strategic monitoring on the neural correlates of prospective memory. Memory \& Cognition, 35, 1034-1046.

Wolf, O. T. (2003). HPA axis and memory. Best Practice \& Research Clinical Endocrinology \& Metabolism, 17, 287-299.

Wolf, O. T. (2009). Stress and memory in humans: Twelve years of progress? Brain Research, $1293,142-154$.

Wolf, O. T. (2008). The influence of stress hormones on emotional memory: Relevance for psychopathology. Acta Psychologica, 127(3), 513-531.

World Health Organization. (2001). Mental health: New understanding, new hope. Geneva, Switzerland: Author. 
Yerkes, R. M., \& Dodson, J. D. (1908). The relation of strength of stimulus to rapidity of habit formation. Journal of Comparative Neurology and Psychology, 18, 459-482.

Young, A. H., Sahakian, B. J., Robbins, T. W., \& Cowen, P. J. (1999). The effects of chronic administration of hydrocortisone on cognitive function in normal male volunteers. Psychopharmacology (Berlin), 145(3), 260-266.

Zollig, J., West, R., Martin, M., Altgassen, M., Lemke, U., \& Kliegel, M. (2007). Neural correlates of prospective memory across the lifespan. Neuropsychologia, 45, 3299-3314. 